\title{
EFFECTS OF PERSONAL AND ENVIRONMENTAL FACTORS ON SOCIAL ENGAGEMENT IN LATER LIFE
}

A Dissertation
Presented to
The Faculty of the Graduate School
University of Missouri
In Partial Fulfillment
of the Requirements for the Degree
Doctor of Philosophy
JuLY 2009
Debra Parker-Oliver, Dissertation Supervisor


The undersigned, appointed by the Dean of the Graduate School, have examined the Dissertation entitled

\title{
EFFECTS OF PERSONAL AND ENVIRONMENTAL FACTORS ON \\ SOCIAL ENGAGEMENT IN LATER LIFE
}

\author{
Presented by Seema Sehrawat, \\ a candidate for the degree of doctor of philosophy, \\ And hereby certify that, in their opinion, it is worthy of acceptance.
}

Dr. Debra Parker-Oliver

Dr. Martha Markward

Dr. Angela Curl

Dr. James Hinterlong

Dr. David Oliver 
I dedicate this dissertation to my loving parents and my Guru

Mr. Azad Singh Sehrawat, Mrs. Kanta Devi, and Mr. Ranjan Dhar Their encouragements have served as an inspiration for pursuing a $\mathrm{PhD}$ 


\section{ACKNOWLEDGEMENTS}

I would like to acknowledge and give special thanks to my chair and mentor, Dr. Debra Parker-Oliver, whose constant support, encouragement, and patience have culminated in the completion of this dissertation. Her confidence in me is unwavering and her commitment towards my advancement remains relentless. She is someone I can count on - someone I trust, respect, and look forward to learning from throughout my academic career. Completion of this journey would not have been possible without the generous support of my committee members, Drs. Martha Markward, Jim Hinterlong, Angela Curl and David Oliver. I am very thankful to all of them for their guidance and willingness to share their knowledge and expertise throughout my doctoral studies. A special thanks to Ms. Jane Bierdeman-Fike and Philanthropic Educational Organization for the Jane Bierdeman-Fike Doctoral Fellowship Fund in Social Work and Philanthropic Educational Organization International Peace Scholarship. These scholarships provided essential financial support during my doctoral studies.

I would like to thank my family and friends for their prayers, strength, love and support. To my mother and father, who believed in me and encouraged me to overcome any obstacle in my life. They have instilled in me a love of learning and always supported my attempts at new endeavors. To my brothers Sunder, Joginder and Ravinder and sisters Rajni and Ritu, thank you for your love and encouragement as I strove to reach my goals. Finally, my mentors Dr. Nalini Rangnathan and Mr. Ranjan Dhar, I would like to thank you for your inspiring words, and the importance of education your have instilled in me. 
Finally, I would like to acknowledge my better half, Dhinendra Lohmor, for his continuous love and support to complete my doctoral studies. There have been many other people who have helped me make this dream come true, and I am forever grateful. 
TABLE OF CONTENTS

ACKNOWLEDGEMENTS...........................................................

LIST OF TABLES .................................................................iii

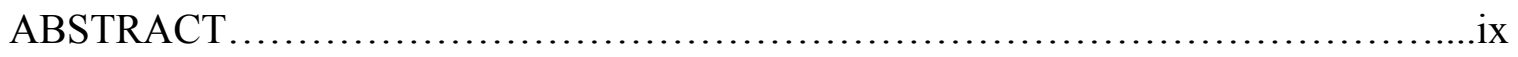

Chapter

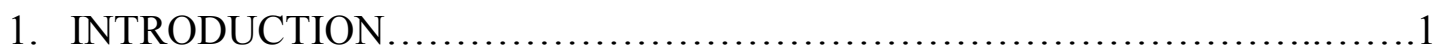

Conceptual Framework

Statement of Problem

Significance of the Study

Statement of Purpose

Definitions of Terms

Engagement

Community-dwelling Older Adults

Personal Factors

Community and Environmental Factors

Assumptions

Limitations

Delimitations

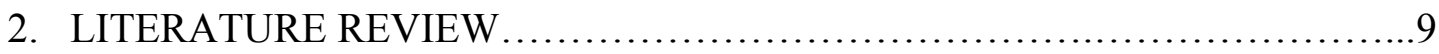

Community-dwelling Older Adults

Conceptual Framework 
Dimensions of engagement

Patterns of Productive Occupations

Volunteerism in Later Life

Productive Activities

Paid Work

Helping Activities

Social and Domestic Activities

Participation in Religious Activities

Consequences of Engagement

Continued Well-being through Productive Participation

Effects on Physical Health, Mental Health and Mortality

Determinants of Engagement

Income

Education

Health

Gender

Marital Status

Age

3. METHOD OF STUDY

Null Hypotheses

Participants

Study Sample

Measures 
Study Design

Dependent Variables

Independent Variables

Data Analysis Plan

Bivariate Analyses

Multilevel Modeling

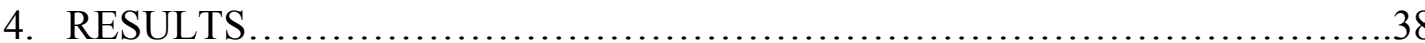

Target Population

Characteristics of Participants

Characteristics of Communities

Bivariate Analyses

Predicting Social Engagement

Research Question 1

Research Question 2

Predicting Participation in Religious Activities

Research Question 1

Research Question 2

Predicting Participation in Social Activities

Research Question 1

Research Question 2

Predicting Participation in Family Activities

Research Question 1

Research Question 2 
5. DISCUSSION

Summary of Key Findings

Discussion

Individual Characteristics

External facilitators

Factors Associated with Participation in Religious, Family and Social

Activities

Implications

Policy

Practice

Research

Conclusion

\section{APPENDIX}

A. Conceptual Framework...............................................61

B. Tables........................................................... 62

C. Variables from CPOA 2002 Survey used in the Study.......................82

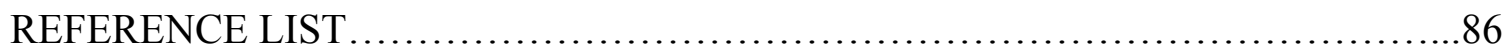

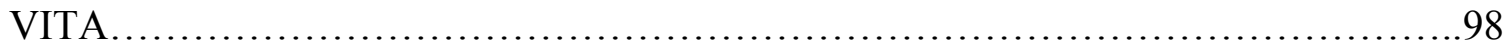




\section{LIST OF TABLES}

Table

1.1 Final Sample Sizes and Response Rates, By Site ............................ 38

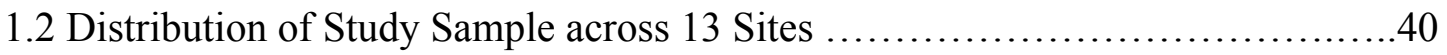

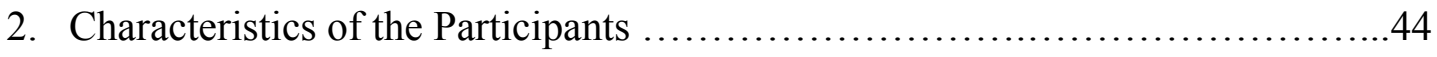

3. Means, Standard Deviations and InterCorrelations of the Variables at Level-

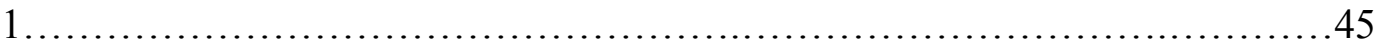

4. Analysis of Variance for differences in Social Engagement..................49

5. T-Tests for differences in Social Engagement .............................50

6. Summary of Multilevel Modeling for Variables Predicting Older Adults Social Engagement........................................................ 51

7. Summary of Multilevel Modeling for Variables Predicting Older Adults Participation in Religious Activities......................................53

8. Summary of Multilevel Modeling for Variables Predicting Older Adults Participation in Social Activities.........................................54

9. Summary of Multilevel Modeling for Variables Predicting Older Adults Participation in Family Activities. 


\title{
EFFECTS OF PERSONAL AND ENVIRONMENTAL FACTORS ON
}

\section{SOCIAL ENGAGEMENT IN LATER LIFE}

\author{
Seema Seema \\ Dr. Debra Parker-Oliver, Dissertation Advisor
}

\begin{abstract}
The study used data from Community Partnerships for Older Adults (CPOA) Program Survey of Older Adults 2002 to identify factors that predict social engagement. Multilevel modeling was used to examine the association of demographic and community-level variables with social engagement.

Nearly all older adults were socially engaged in at least one of the three activities. Gender, education, being retired, good health, one or more number of living children, income, someone to take care in case of emergency and length of stay in the community were significant predictors of social engagement. However, unlike the previous literature, age and marital status were not. Further, influence in making community a better place to live; interest of local officials towards needs and concerns of the older adults; and knowledge of available services significantly predicted social engagement.

This study suggests that community and the relationships within the community are important inspite of individual differences among older adults and therefore Development of resources, supportive services and polices that would promote engagement in various religious, social and family activities among community-dwelling older adults, is desired. In conclusion, consideration of individual characteristics and community variables while designing programs for older adults may increase social engagement.
\end{abstract}




\section{Chapter One: Introduction}

With advancements in medicine and clinical research, life expectancy is increasing 2.3 years per decade (Westendorp, 2006). On the heels of the current older generation are 69 million so-called "baby-boomers" (Kellet, 2004), with the average life expectancy exceeding 76 years (Butler, 2002). Of these, many will live well into their nineties. The majority of elders, especially the young old between 65 and 74 years of age, are healthy and remain capable of being productive (Choi \& Dinse, 1998). With an overall high level of aptitude, education, and expertise, it seems realistic to expect that many in this cohort will continue living productive lives (Kellet, 2004).

Researchers have conducted studies analyzing the impacts of productive aging in later life and found a significant relationship between various forms of engagement and well-being (Bambrick \& Bonder, 2005; Conner, Dorfman, \& Thompkins, 1985; Mathers \& Schofield, 1998; Menec, 2003; Rozario, Morrow-Howell, \& Hinterlong, 2004; Stevens-Ratchford \& Cebulak, 2004; Thompson, 1973; Wahrendorf, Von dem Knesebeck, \& Siegrist, 2006). Assessing this influence requires consideration of demands posited by environmental factors, especially the immediate surroundings, the community and the larger socio-political context. Further, the availability, accessibility and utilization of various supportive services in the community are indicative of social engagement among older adults. Individual differences within this population may also account for the differential participation in later years (Hinterlong, 2006; Hinterlong, Morrow-Howell, \& Sherraden, 2001). 
Assessment of involvement as one ages is given additional meaning when personal and environmental factors are considered in the model. Considering this analytic discussion, several questions can be proposed about the social engagement of older Americans. What factors best explain engagement in later life? Do personal factors play a major role, above and beyond environmental factors, in predicting the activities older adults engage in? And, to what extent does the knowledge of available resources in the community influence/enhance social engagement?

\section{Conceptual Framework}

The relevance of social exchange theory as a conceptual framework guiding research on various aspects of aging is widely accepted (Call, Finch, Huck, \& Kane, 1999; Keyes, 2002; Newsom, Nishishiba, Morgan, \& Rook, 2003). Exchange provides meaning and is an intricate part of one's everyday life. Social exchange theory is helpful in categorizing and making evident the resources exchanged between older people and the society at large. Social exchanges are embedded in lives of older adults and serve as a means of structuring routines and are a basis for continued engagement in life (StevensRatchford \& Diaz, 2003). The resource exchange theory guides this research and falls under the umbrella of social exchange theories.

The resource exchange theory by Foa and Foa (1974) proposes six types of resources exchanged by individuals in an exchange relationship. The first, love, is defined as "an expression of affectionate regard, warmth, or comfort" (Donnenwerth \& Foa, 1974, p. 786). The second, status, is defined as "an evaluative judgment conveying high or low prestige, regard, or esteem"; information a third type of resource is defined as "any advice, opinions, or instructions" (p. 786). Fourthly, money is defined as "any coin 
or token that has some standard of exchange value" (p. 786). The final two resources are goods and services. Goods are defined as "any products or objects; and services as "activities on the body or belonging to the individual" (p. 786). Foa and Foa (1974) looked at these resource categories from the dual dimensions of concreteness and particularism. Particularism indicates "the extent to which the value of a given resource is influenced by the particular persons involved in the exchange" (p. 80) and concreteness "suggests the form or type of expression characteristic of the various resources" (p. 81). Older people exchange most of these resources and often this exchange relationship is influenced by their individual characteristics and various resources in the environment. Examining these individual characteristics and resources is therefore vital for measuring their effect on social engagement. The resource exchange theory of Foa and Foa (1974) also provides an explanation of various gains older adults may obtain from social interactions. If their needs are met through exchange with persons and/or environment who can provide them with resources and to whom they can give resources, the likelihood of their feeling satisfied with their relationships and with life in general increases.

The dynamic relationship and exchange between older adults and their environment may explain the level of engagement among older adults regardless of noticeable decline in capacities as people age. Individual factors such as age, gender, and personal preferences may also influence engagement. Therefore, evaluating the level of engagement among this cohort requires attention to both the personal and environmental factors. 


\section{Statement of Problem}

A considerable number of studies have predicted the affects of engagement on coping with health changes in later life (Bukov, Maas, \& Lampert, 2002; Menec, 2003) and wellbeing (Bambrick \& Bonder, 2005; Conner et al., 1985; Mathers \& Schofield, 1998; Rozario et al., 2004; Stevens-Ratchford \& Cebulak, 2004; Thompson, 1973;

Wahrendorf et al., 2006). A small number of researchers have focused on the personal characteristics like gender, education and socio-economic status, in predicting engagement (Hinterlong, 2006; Mjelde-Mossey \& Chi, 2004; Van der Meer, 2006).

Further, a few researchers have examined the personal and environmental determinants of activity involvement among older adults residents of congregate facilities (Lawton, Nahemow, \& Teaff, 1975; Lemke \& Moos, 1989; Sherman, 1974). However, the impact of personal and environmental factors on engagement among community-dwelling older adults has not been evaluated.

Evidence suggests that engagement in life is beneficial and productive roles are helpful when there is low level of informal social support (Rozario et al., 2004); however, there is very little research that has examined the causes of disparities in engagement among community-dwelling older Americans (Peters-Davis, Burant, \& Braunschweig, 2001). Specifically, there is a dearth of research focusing on environmental and personal factors that could determine or enhance active engagement among community-dwelling older adults. As a result policymakers, practitioners, and researchers are left without needed information to take desirable measures to enhance engagement among older adults. 


\section{Significance of the Study}

Various studies confirm a positive relationship between social engagement, physical and mental health along with beneficial influence of social engagement on survival (Bambrick \& Bonder, 2005; Bukov et al., 2002; Herzog, Ofstedal, \& Wheeler, 2002; Menec, 2003; Rozario et al., 2004; Stevens-Ratchford \& Cebulak, 2004;

Wahrendorf et al., 2006). Likewise, lack of engagement in later years may negatively impact the overall well-being and survival of older adults. Hence, researchers need to identify the factors that promote engagement among older adults so that policy makers and practioners can support and facilitate engagement in later life.

Older adults respond and react better in their own surrounding (Smith, 2003). Research also indicates that older adults prefer to remain in their homes as they age, in spite of disabilities (Cook, 2007). Parallel to that, it can be hypothesized that dining with others, social routines, and involvement in the community interest groups and religious and travel activities may be a vehicle for continual involvement in life and persistently high functioning. With an expected increase in the older adult population, most of whom want to stay in their own homes, it can therefore be assumed that the number of people in need of various resources within the community will continue to grow rapidly. The link between personal and environmental factors on aging and the impact of available of resources, like senior centers, on activity needs to be researched.

Understanding the relationship between various personal and environmental aspects influencing engagement has implications for elder advocates, policymakers and academicians. Striving to change the image of older adults as frail, dependent and worthless along with examining the association of these variables with engagement is 
important to redefining stereotypes. Recognizing this perspective is also important for social workers interested in enhancing the quality of life for older adults through active engagement.

\section{Statement of Purpose}

The purpose of this study is to examine the influence of different personal and environmental factors on social engagement of community-dwelling older adults. The objectives of the study were to: (a) determine which personal and environmental factors best explain engagement in later life; (b) study whether personal factors alone play a major role in determining the kind of activities older adults engage in; and (c) identify which aspects of the community are related to social engagement. For that reason, the following research questions were asked:

1. What factors predict social engagement in later life?

2. Do perception of community and knowledge of services mediate the relationship between individual characteristics and social engagement?

\section{Definitions of Terms}

The contemporary literature overlaps in the use of terms like productive aging, productive engagement, civic engagement and successful aging. For the purpose of this study the term engagement is defined in a more holistic way.

\section{Engagement}

Engagement encompasses regenerative, productive and consumptive activities, whether social or solitary. These include work, informal and formal volunteering and caregiving in/out of familiar environmental/cultural surroundings, including meeting friends, reading a novel, watching TV, participating in paid and unpaid community work, 
staying up to date on news, and helping a neighbor (Reid, 1934). The study focuses on social engagement, which was operationalized using the following variables from the 2002 Community Partnerships for Older Adults Survey (CPOA): (a) participation in the church or other worship activities; (b) participation in a social activity such as watching a movie, play, concert, going to a restaurant, sporting event, and club meeting, etc.; and (c) getting together with friends, neighbors and family.

\section{Community dwelling older adult}

These are individuals who are 50 years of age or older who live in their own homes with or without a significant other. The concept was operationalized in the study as individuals participating in the CPOA survey of 2002.

\section{Personal factors}

Personal factors are individual characteristics such as age, education, income, and health status. The concept was operationalized in the study using the following variables from the 2002 CPOA survey: (a) gender, (b) marital status, (c) income, (d) educational attainment, (e) health, (f) length of stay in community, (g) age, and (h) someone to call in case of emergency.

\section{Community and environmental factors}

Community and environmental factors are conditions in the environment, such as perception of community as a place to live and local officials considering needs and concerns of the older adults. The concept was operationalized in the study from the 2002 CPOA survey using the following variables: a) Knowledge of available services (senior center, adult day program, housekeeping services, senior lunch programs, telephone helpline, home repair assistance, visiting nurse service, personal assistance, door-to-door 
transportation, nursing home, assisted living facility and hospice care), (b) rating of community as a place to live, (c) local officials taking into account interest and concerns of older adults, and (d) perception about having influence in making the community a better place to live.

\section{Assumptions}

1. Personal and environmental factors impact social engagement in later life.

2. Knowledge of available services, some social support and a senior-friendly community constitute the social climate that is desired for social engagement among older adults.

\section{Limitations}

1. Biases may be inherent in self-reported information.

2. The determinants of social engagement among community-dwelling older adults may be different for those residing in long-term care facilities.

3. The findings of this study may not be relevant to rural communities as the data for this study was collected from urban or sub-urban settings.

\section{Delimitations}

1. Hierarchal multilevel modeling was used as a means to explore which factors influence engagement.

2. This study focuses primarily on the determinants of engagement among community-dwelling older adults and is delimited by the 5,298 older adults who participated in 2002 CPOA survey. 


\section{Chapter 2: Literature Review}

The aging process includes physical, social, psychological, and spiritual changes and implies dual adjustments required at the individual and environmental level. The presence of community resources, social networks, and various individual factors like education and income may influence the level of engagement among communitydwelling older adults. This literature review provided a context in which to consider social engagement among older adults and answered the following questions: What are the dimensions of engagement in later life? To what extent is engagement in later life beneficial? And what are the determinants of social engagement among communitydwelling older adults?

\section{Community-dwelling Older Adults}

Most Americans prefer to age in the same communities where they have lived, often for many years ("Maturing of America," 2007). In 2001, 21.8 million houses were owned by older adults 65 or older (“U.S. Census Bureau”, 2002). Further, a large number of baby boomers who are staying in their own homes are approaching old age in good health and with significant amount of time in their hands for social engagement. Therefore, every community, from fast growing suburbs to more stable rural areas, will need to adapt to this maturing population wanting to live in their homes ("Maturing of America", 2007). Although meeting the needs of an aging population is on the nation's policy agenda (Black \& Brown, 2004), strategies to improve awareness about future care issues and to increase access to related services in communities are necessary for keeping older adults in their own homes. 


\section{Conceptual Framework}

Role theory and activity theory commonly guide research on social activity in later life. Role theory is used in specific discussions about multiple role occupancy in later life and the impact of engagement in these roles on well-being (Hinterlong et al., 2001; Hinterlong, Morrow-Howell \& Sheraden, 2007; Rozario et al., 2004). Similarly, activity theory proposes that the frequency and level of intimacy of activity participation is vital to well-being (Pai, 2008). Researchers have used this theory to guide them in measuring higher levels of activity, either by focusing on the range of activities or the frequency with which older adults engage in various activities (Menec \& Chipperfield, 1997). Regardless of the noticeable decline in people's capacities as they age, participation in various activities may be influenced by the dynamic exchange between older adults and their environment. However, role theory and activity theory of aging do not focus on personal and community characteristics which may influence social engagement among older adults. Yet measuring active engagement requires emphasis on both the personal and environmental factors.

Resources exchanged by community-dwelling older adults may shape their engagement in later life. The resource dependency theory by Foa and Foa (1974) described six possible types of resources exchanged by individuals in a society from a dual dimension. Therefore, resource exchange theory facilitated the development of a conceptual framework for this research. This conceptual framework informs and guides the research questions. 


\section{Dimensions of Engagement}

In the existing discourse on older adults, the terms civic engagement, productive engagement, productive aging and successful aging are used interchangeably. It is important to define these terms to determine their overlap. Civic engagement consists of broad array of "activities, including voting, being involved in political campaigns, participating in paid and unpaid community work, staying up to date on news and public affairs, and helping one's neighbor” (Martinson \& Minkler, 2006, p. 319).

Rowe and Kahn (1998) proposed a definition of successful aging. It encompassed three components: low probability of disease, high functioning, and active engagement with life. They further divided active engagement in two parts: activity and social support.

In the process of defining the term productive aging, gerontologists sought to define the term productivity. From early 1980 s to 1990 s, the definition of productivity shifted from activities that produce goods and services without pay, to activities producing goods and services, whether paid or not, including activities like housework, childcare, volunteer work, and help to family and friends (Herzog, Kahn, Morgan, Jackson, \& Antonucci, 1989). The focus of these definitions was on economic and sociological aspects of aging ignoring psychological or physiological components (O'Reilly \& Caro, 1994).

In the early $21^{\text {st }}$ century a new term "productive engagement" was coined. The third party criteria introduced by Reid (1934) separated production from its financial aspects. Productive engagement was seen more as an activity which is performed predominately for its outcomes. These activities were divided into two subgroups: 
productive, which can be delegated to third party without loss of any beneficial effect (e.g., doing laundry, cleaning, running errands) and consumptive, which cannot be delegated to a third party without loss of benefits (e.g., meeting friends, reading a novel, watching TV). Both productive and consumptive activities were not performed for the expected utility of their outcomes, but because for their own sake as they are rewarding in themselves (Klumb, 2004).

In conclusion, productive engagement encompassed regenerative, productive, and consumptive activities and their rewards for individual and society. Meanwhile, civic engagement involved political participation and civic volunteerism. Successful aging emphasized low probability of disease, high cognitive, and physical functioning along with engagement with life. The definitions of successful aging and civic engagement did not see high cognitive and physical function as the result of engagement in life. Rather, health and engagement in life moved parallel instead of engagement being the cause and health its effect. It is important to discuss the overlap between these terms and provide a clear definition of the term engagement.

\section{Patterns of Productive Occupations}

The importance of productive occupations is readily accepted among the aging population and is noticeable in their day-to-day behaviors. Bukov and colleagues (2002) found that the numbers of very old who do not participate in social activities has declined. They report that the reason for increase in number of older person's participation was a fear of social dying, because for them, it was equivalent to physical dying. Similarly, in a study of older people living well with arthritis, it was found that engaging in social occupation fulfilled the need to be productive and promoted health 
(Stevens-Ratchford \& Cebulak, 2004). Dining with others, social routines, and involvement in the community interest groups and religious and travel activities were discovered as a vehicle for continual involvement in life and persistently high functioning (Stevens-Ratchford \& Cebulak, 2004). According to Menec (2003), different activities were related to different outcome measures but generally, more social and productive activities leads to happiness, higher function and reduced mortality. Meanwhile, solitary activities (e.g., handwork hobbies) were related to happiness and have more psychological benefits by providing sense of engagement with life in later years (Menec, 2003). Therefore, both solitary and social activity can have positive effects on the health and psychological well-being of older persons.

In the view of Stevens-Ratchford and Cebulak (2004) occupations provide meaning and are an intricate part of one's everyday life. They also suggests that occupations are embedded in lives of older adults and serve as a means of structuring routines providing a basis for continued engagement in life. Bambrick and Bondor (2005) found that productive/social occupation demonstrates worth and value of older persons and gives them an identity. Also, staying productive, whether paid or unpaid, and giving back to community, contributed to self-concept of older persons and allowed them to feel engaged with life. They also found volunteer and care-giving activities made the target group feel engaged and worthwhile. For that reason, Bambrick and Bondor (2005) contend that productive occupations, whether social or solitary, influence self-concept and provide an older person with a feeling of being valued and helps in aging productively. 


\section{Volunteerism in Later Life}

Active engagement in later life is one of the cornerstones of successful aging and volunteering is a pathway to remain actively engaged in later life (Mjelde-Mossey \& Chi, 2004). A study by Peters-Davis and colleagues (2001) suggested volunteering as a life satisfaction process and an activity that benefits the society. In the United States, older volunteers comprise a significant proportion of the total population who volunteers (Black \& DiNitto, 1994; Cnaan \& Cascio, 1999; Marriott Senior Living Services, 1991). Increased participation of older adults in volunteer work is related to their longer life expectancy, better health conditions, and improved education (Cheung, Tang, \& Yan, 2006). It was found that older adults are motivated towards volunteering by both altruistic and self-oriented needs, such as filling the vocational void left by retirement, being a useful member of the society by helping others, and finding a new peer group (Barlow \& Hainsworth, 2001). It was also found that volunteer work was associated with better activities of daily living (ADL) functioning (Berkman, Seeman, \& Albert, 1995).

\section{Productive Activities}

Using the Commonwealth Foundation Survey of Productive Aging, Caro and Bass (1995) found that older adults between the ages of 55 and 74 remain active along a number of dimensions of productive aging (defined as volunteering, child care, informal help to friends, relatives and neighbors, caregiving, paid work, and education). Similarly, Klumb and Baltes (1999), employing data from the Berlin Aging Study, found that more than $90 \%$ of persons aged 70 to 84 and nearly $80 \%$ of those 85 and older participated in productive activities (domestic activity including home maintenance and housework, errands, gardening, paid work, and helping others including caregiving and formal 
volunteering). Productive activities were also found to be protective of ADL status among older adults. A study by Luoh and Herzog (1999) found that there was a reduced risk of having any ADL limitation for several years, among people who were working for pay or volunteering.

Paid Work. A considerable amount of literature has documented patterns of participation in paid work among older adults. Workforce participation has increased for older men and dramatically for older women (Harvard School of Public Health/Metlife Foundation, 2004; Seongsu \& Feldman, 2000). According to Herzog, Kahn and colleagues (1989), over the life course patterns of participation in paid work resembles an inverted $\mathrm{U}$, where paid work activities increase as men and women approach midlife and then are reduced or eliminated as they enter later life. Although paid work does occur among a significant minority of the older population, it is less common beyond the age of 70 or 75 (Szafran, 2000).

Helping Activities. The literature on caregiving by older adults is an example of the provision of emotional and instrumental social support by older adults (Herzog, Ofstedal, et al., 2002). Research has demonstrated that providing informal help to friends and family members such as helping with chores or child care, running errands, and providing transportation, is common among older Americans (Doty, Jackson, \& Crown, 1998). Many older individuals provide care for a spouse (Herzog, Kahn, et al., 1989). Gender differences also exist in terms of types of care provided. While men's participation often occurs at the level of care coordination, women are somewhat more likely than men to provide direct care (Johnson \& LoSasso, 2000). 
Social and Domestic Activities. The most common form of engagement is the direct interaction with friends, family members, relatives and neighbors. These interactions take place through outings, dining together, visits, phones calls and joint participation in social groups, etc. They also involve exchange of social support and extending informal help. Often times, participation in organizations and attending community meetings also fall under the purview of social activities (Herzog, Ofstedal, et al., 2002). Leisure activities which are above and beyond professional, social and family commitments (West, Delisle, \& Simard, 1996) provide avenues for new or expanded roles in older age with a continued sense of engagement in life. These can encompass almost any activity ranging from highly formalized to much less formalized activities, such as attending club meetings, or going on outings and tours with friends and family, gardening or cooking, and taking computer or language classes (Herzog, Ofstedal et al., 2002).

\section{Participation in Religious Activities}

Churches and religion are important part of older people's lives and provide them an avenue to stay engaged in later life (Taylor, Chatters, \& Jackson, 2007a). Religious activities also have a social element and provide opportunities for older adults to exchange resources. Several studies have documented gender and income difference in religious service attendance (Taylor, Chatters, \& Jackson, 2007a, 2007b; Taylor, Chatters \& Levin, 1992). Similarly, studies have found age, martial status, and education to be an important predictor of participation in religious activities (Taylor \& Chatters, 1991; Taylor, Chatters \& Jackson, 2007a; Taylor, Chatters \& Levin, 1992). 


\section{Consequences of Engagement}

An extensive literature has documented the affects of engagement on health and well-being of older adults. A positive relationship has been shown between engagement, physical health and mental health. Similarly, lower mortality risks have been found among persons continue to engage in various social relationships and activities (Bambrick \& Bonder, 2005; Bukov et al., 2002; Glass, Mendes de Leon, \& Marottoli,1999; Herzog, Ofstedal et al., 2002; Hultsch, Small, \& Hertzog, 1999; Mendes de Leon, Glass, \& Beckett, 1999; Menec, 2003; Musick, Herzog, \& House, 1999; Ofstedal, Wheeler, \& Herzog, 2000; Rozario et al., 2004; Stathi, Fox, \& McKenna, 2002; Stevens-Ratchford \& Cebulak, 2004; Unger, Johnson, \& Marks, 1997; Wahrendorf et al., 2006).

\section{Continued Well-Being through Productive Participation}

Well-being is a broad term incorporating quality of life, life satisfaction, social interaction and productive exchange. Well-being is an important outcome for exploring the effect of productive aging in later life. A study by Wahrendorf and colleagues (2006) confirms an association between productive activity and well-being. They established that being active in all three types of social productivity (voluntary work, care for a person, and informal help) is associated with higher mean scores of well-being. Furthermore, they found that the mean well-being scores were lower where there was non-reciprocity of exchange. Findings were consistent with the theoretical framework that the association varies with the quality of social exchange as it is dependent on the efforts spent and rewards received (Wahrendorf et al., 2006). 
A study on social participation among very old people found that such activity is a means of coping with health changes in later life. It also suggested that increased social participation may play a role in quality of life, giving a feeling of usefulness for others, providing personal fulfillment, and enhancing self-respect (Bukov et al., 2002).

Reinforcing it further, Stevens-Ratchford and Cebulak (2004) showed that "social occupations enabled participants to enrich the lives of others and continued to ensure a sense of well-being and pride" (p. 47). They found that productive exchange and social interaction strengthened family bonds, helped people cope with arthritis, and provided direction in managing arthritis symptoms and other life challenges (Stevens-Ratchford \& Cebulak, 2004), hence enabling the older person to attain well-being in all spheres of life. Menec (2003) used the variables happiness and life satisfaction as outcome measures of well-being. He found that although activity level declined with age, older age was not correspondingly linked to less happiness and was just a shift from more demanding activity to a less demanding one(s). Therefore, several social, solitary and productive activities were positively related to happiness and life satisfaction in later life. He reports, "these findings can be interpreted in terms of compensatory mechanisms that allow people to maintain psychological well-being when faced with age-related losses" (Menec, 2003, p. S80).

Rozario and colleagues (2004) found positive impacts of productive activities on self-rated health. They suggested that productive roles are helpful when there is low level of informal social support and found that lower lever of informal social support among caregivers without engaging in any productive activity were related to functional impairment (Rozario et al., 2004). The research by Wahrendorf and colleagues (2006) 
suggested that performing a role beyond employment is beneficial for well-being and that the level of exchange whether reciprocal or non-reciprocal influence well-being. These studies found a positive correlation between productive participation and well-being. Effects on Physical Health, Mental Health and Mortality

Engagement in later life has measurable impact on physical health and cognitive outcomes. Stevens-Ratchford and Cebulak (2004) stated that thinking in new and creative ways, understanding life from the eyes of others, sharing knowledge, participation in social, political and religious discussions and events along with physical activities, results in higher functioning. Cognitive activity stimulates the mind and enhances functioning by demanding use of cognitive and physical abilities, and it promotes health. In the same study, social engagement improved functioning by providing a positive outlook for the future. Participants focused on life rather than arthritis, thus finding joy and pleasure through social engagement.

A study conducted by Menec (2003) measured function in terms of combining physical and cognitive functions. He suggested that engaging in various social and productive activities was related to reduced functional decline and was depicted in terms of physical benefits and greater longevity. Activity level was also related to better function and reduced mortality six years later (Menec, 2003). It was also found that older persons continue engagement regardless of their limiting health conditions (Peters-Davis et al., 2001) and switch to less demanding activities (Menec, 2003).

In a study of older community-dwelling persons, it was found that being involved in social networks of family and friends was protective against ADL decline and enhanced recovery from ADL disability (Mendes de Leon et al., 1999). Similar results 
were shown in a study focusing on broader measure of social interaction. After controlling for physical activity, the study results concluded that social interaction had an independent protective effect on functional health over a 6-year period and that it buffered the negative influence of widowhood on functional decline (Unger et al., 1997).

In conjunction with noticeable benefits for physical health, engagement in later life appears to have some positive influence on various aspects of mental health. There are several cross-sectional and longitudinal studies that suggest a beneficial effect of engagement on both level and change in cognitive performance (Herzog, Ofstedal, et al., 2002). Using data from the Seattle Longitudinal Study, Schaie (1984) found that higher engagement was negatively associated with amount of intellectual decline over time. Similarly, a study conducted by Fabrigoule, Letenneur, and Dartigues (1995) on older persons in France, after controlling for age, baseline cognitive performance, occupational activities, and physical capability, found that the risk of incident dementia was half among older adults who engaged in leisure activities than who did not engage in these activities. Other studies also found beneficial effects of leisure activities (Menec, 2003) and lifestyle engagement (Hultsch et al., 1999) on intellectual performance. Further, a cross sectional study found that intellectual or educational activity, social activities and certain productive activities (e.g., preparing a meal or shopping) were associated with higher level of cognitive functioning (Hultsch et al., 1999).

Affective mental health also seems to be influenced by level and quality of social engagement. It was found that physical activity appears to contribute to the mental health of older adults through maintenance of a busy and active life, mental alertness, positive attitude toward life and avoidance of stress, negative function, and isolation (Stathi et al., 
2002). Further, while controlling for baseline depressive symptoms and key covariates, Ofstedal and colleagues (2000) found that productive and social activities were associated with fewer depressive symptoms. In a study on middle and older-aged adults, Ingersoll-Dayton, Morgan and Antonucci (1997) distinguished between positive and negative social exchanges with friends and family. The study suggested strong associations between the number of positive social exchanges and positive affect and between the number of negative social exchanges and negative affect.

Caregiving is a common role which older people engage in, in their later life. Various studies on caregiving have found both negative and positive effects on the mental health of those providing care. Rozario and colleagues (2004) found that caregivers with at least one more productive role were notably better in their self-rated health, however, they were not able to find supporting evidence on functional impairment and depressive symptoms using the theoretical concepts of role enhancement and role strain perspective. A recent study of spouse caregivers suggested that situations involving high levels of caregiver burden resulted in higher levels of anxiety and depression (Beach, Schulz, \& Yee, 2000).

Various studies have revealed protective effects of several types of social activities, leisure activities and productive activities on mortality. The beneficial effect of social engagement on mortality remained even after adjusting for age and other key factors (Herzog, Ofstedal, et al., 2002). Glass and colleagues (1999) in a 13-year prospective study of older adults found that an array of productive activities provided similar advantages for survival as for physical fitness and social activities. A study conducted by Musick and colleagues (1999) confirmed that volunteer work, paid work, 
household maintenance and housework accounted for similar benefits on mortality over shorter period.

When it comes to measuring the benefits of caregiving, it is found that not all forms of social engagement have positive health benefits. A study by Schulz and Beach (1999) reported higher risks for caregivers who were experiencing mental and emotional strain over a period of four years, relative to non-caregivers. Hence, research has shown that caring for an impaired family member or friend may be associated with poorer health outcomes and increased risk of mortality.

In summary, in general the current literature supports the positive effects of productive engagement in terms of physical benefits, positive effects on health, better function, greater longevity, psychological well-being (Menec, 2003), pride, fulfilling the need of being productive (Stevens-Ratchford \& Cebulak, 2004), self-worth and being engaged (Bambrick \& Bonder, 2005). A wide range of activities enhances physical and cognitive functioning in middle and older ages. However, there still exists a debate about the direction of causation, i.e. whether engaging in life benefits physical function and cognition or whether physical and cognitive decline leads to social disengagement (Herzog, Ofstedal, et al., 2002).

\section{Determinants of Engagement}

A few studies have shown that demographic factors such as age and income; personality attributes such as openness to experience and altruism; cultural factors such as perceived importance of volunteering and past volunteer behavior; and situational factors such as perceived opportunity and health, are important variables affecting volunteer behavior in later life (Lammers, 1991; Omoto \& Synder, 1995; Penner \& 
Finkelstein, 1998; Stevens-Ratchford \& Diaz, 2003). Familiar environmental surroundings have also been found to contribute to productive aging, leading to better health and quality of life (Stevens-Ratchford \& Diaz, 2003). A few researchers have also examined disparities based on personal characteristics like income, gender, education, marital status and age in predicting mostly one aspect of engagement, i.e. volunteering (Caro \& Bass, 1995; Chambre, 1993; Fisher, Mueller, \& Cooper, 1991; Fisher \& Schaffer, 1993; Gallagher 1994; Herzog \& Morgan, 1993; Hinterlong, 2006; Marriott Senior Living Services, 1991).

Income

Quite a few studies found a link between income, volunteering and participation in other types of activities. It was found that people with higher income tend to volunteer more (Fischer, Mueller et al., 1991; Herzog \& Morgan, 1993). Another study confirmed the results and found that higher income, along with retirement, was associated with increased levels of commitment among volunteers (Chambre, 1993). A plausible explanation of this phenomenon can be attributed to the ability to cover the extra costs associated with volunteering (i.e., transportation, food, and lodging). It may also mean that older adults with higher income are less likely to be forced to engage in paid work in order to pay bills and therefore have time to volunteer.

\section{Education}

Education is also identified as a factor related to volunteering among older adults. Studies on volunteerism in later life have found that respondents with a college degree were more likely to volunteer than respondents with only a high school education (Fischer et al., 1991; Marriott Senior Living Services, 1991). Further, it was also found 
that education was related to the amount of time spent on volunteering (Fischer et al., 1991).

Health

Various studies (Caro \& Bass, 1995; Fischer et al., 1991) acknowledged that good health among older people increases the chances of volunteering. Chambre (1993) and Fischer and Schaffer (1993) stated that poor health was a cause for termination of volunteer efforts among those who were older than 75. Similarly, Gallagher (1994) found that lack of time and poor health were most common reasons for not volunteering. In contrast, there have been studies that showed that elders continued to volunteer their services and participated in various activities despite of decline in physical function (Fischer et al., 1991; Menec, 2003) and that improvement in health status resulted after volunteering for a period of time (Fischer \& Schaffer, 1993).

Gender

With the global feminization of aging there is a need to consider gender differences when exploring factors associated with volunteerism (Mjelde-Mossey \& Chi, 2004). The Marriott Senior Volunteerism Study (Marriott Senior Living Services, 1991) recognized the fact that there are a large amount of female volunteers but it was found that men spent more time in volunteering. On the other hand, a study of Fischer, Mueller, and Cooper (1991) found opposing facts about the effects of gender on volunteering. According to these researchers, men and women volunteer equally and the differences due to gender were more associated with the type of service chosen than the amount of time committed for serving. For example, women are more active in caregiving responsibilities whereas men may be involved in more physically demanding role. 
Although, there is a belief that women are more likely to volunteer than men because of their roles at home as homemakers, this trend is slowly dissipating as more and more women are entering the labor force (Mjelde-Mossey \& Chi, 2004).

\section{Marital Status}

A few studies reported marital status to be a factor affecting older adults' participation in later life. A study conducted by Chambre (1993) noticed that married people were more likely to volunteer than those who were not married. Expanding it further, it was also noted that marriage increases number of social networks that offer greater possibilities of engagement for both partners. Fischer, Mueller, et al. (1991) stated, "Married people tend to have more income than unmarried people, and the gap in income level may be enough to explain the difference in volunteering by marital status" (p. 185). However, Herzog and Morgan (1993) and Fischer, Mueller, et al. (1991) found no significant relationship between marital status and volunteering. It may also be noted that being married may put caregiving responsibilities on a spouse, hence hindering participation in other activities.

Age

It is evident that with the increase in life expectancy, seniors have more time to volunteer and engage in different activities. An AARP (1988) survey, found higher rates of volunteer participation among those aged 75 and older. The Marriott Senior Volunteerism Study found that people over 80 years of age reported the lowest rate (27\%) of volunteering (Marriott Senior Living Services, 1991). In contrast, Fischer, Mueller and Cooper (1991) stated that "even if rates of volunteering decline with age, 
however, a substantial number of older adults, even among the old-old (75+) and the oldest-old (85+), still continue to volunteer" (p. 184).

There are studies that have examined both personal and environmental determinants of activity involvement among older adults; however their scope is limited to congregate facilities (Lawton, 1985; Lemke \& Moss, 1981; Sherman, 1974). Lawton (1985) found that high-functioning individuals can gain from a higher level of demand from the environment than is optimal for low-functioning individuals. Sherman (1974) argued that for individuals who are inclined towards activity involvement but are partially impaired, the availability of environmental resources is very important. It was further stated that for people who have capacity can overcome these environmental constraints, these resources have little impact on activity involvement. Levels of resident activity also vary substantially with the type of residential settings (Lemke \& Moss, 1981). Further, these studies suggested that the personal characteristics along with facility characteristics like supra personal factors (aggregate characteristics of resident group, etc.), physical features of the facility (proximity of community resources, room size, etc.), policies and services (privacy for individuals, social activity program, structured recreational activities, etc.) and the social climate (support to residents, independence, openness, spontaneity and resident autonomy) may influence the level of participation among residents.

A study by Peters-Davis and colleagues (2001) advocated for developing more volunteer-friendly activities and transferring of information about the available opportunities to the older persons, so that their participation can be enhanced. Research focusing on examining engagement in life through aging in place, productive occupation 
and successful aging, found that familiar environmental surroundings provide stability and contributes to successful aging (Stevens-Ratchford \& Diaz, 2003). According to Stevens-Ratchford and Diaz (2003), data reveals that home is a place of activity, occupation and accomplishment, which provides a source of well-being and makes the older person feel good about themselves. In conclusion, individual, demographic, economic, social and cultural factors need attention while designing models of engagement for older adults to enhance their physical and emotional health. Furthermore, there is a need to examine the interaction of personal and environmental factors determining engagement among the seniors residing in their own communities.

Various forms of engagement and their impact on health are well established in the literature; however, little research has focused on the antecedents of social engagement. Additional research is needed to understand the extent to which personal and environmental factors effect engagement in later life. Results from such a study would assist researchers, policy makers, and practioners in acknowledging individual differences and establishing programs that may enhance active engagement among community-dwelling older adults. 


\section{Chapter 3: Method of Study}

Chapter 1 presented an overview of the study and introduced the notion that various factors may determine engagement. Chapter 2 highlighted the literature related determinants and consequences of social engagement. Chapter 3 describes the participants in the study, the materials used to conduct the study, the research design, and analysis techniques.

The variables for this study are operationalized with the 2002 CPOA survey. Statistical analysis of variables in this database answered the research questions. It also helped to test the identified null hypotheses at the .05 level of significance.

\section{Null Hypotheses}

Analysis of the results involved testing the following null hypotheses at the .05 level of significance:

1. Individual factors, perception of community and knowledge of services are not associated with social engagement.

In contrast, the alternative hypotheses were that the following individual factors would increase the likelihood of social engagement: younger age, being female, being married, higher education, being retired, good health, having children, higher income, having someone to call in case of emergency, and longer duration of residence in community. Alternative hypotheses for perceptions of a community are that higher community rating, ability to influence the community and believing that local officials are interested in helping older adults all would increase the likelihood of social 
engagement. Finally, I hypothesized that knowledge of services available in the community would increase social engagement.

2. Perceptions of community and knowledge of services do not mediate the relationship between individual characteristics and social engagement.

In contrast, the alternative hypotheses were that both community perceptions and knowledge of services will reduce or eliminate the magnitude of the relationship between individual factors and social engagement.

\section{Participants}

The participants in the 2002 CPOA survey included 5,298 adults between 50 and 85+ years of age (Black \& Brown, 2005). The survey was part of the Robert Wood Johnson Foundation initiative aimed at improving organization and delivery of long-term care and supportive services for older adults through local public-private community partnerships. It was designed as one component for evaluating the CPOA Program. Representative samples of older adults 50 years of age and older were obtained from 13 communities that were awarded development grants by the program (Brown \& Black, 2005). The communities involved were: (a) Boston, Massachusetts; (b) Broome County, New York; (c) Chittenden and Grand Isle Counties, Vermont; (d) El Paso County, Texas; (e) Harris County, Texas; (f) Maui Island, Hawaii; (g) Milwaukee County, Wisconsin; (h) Riverside County, California; (i) St. Clair County, Michigan; (j) San Francisco County, California; (k) Columbia and Union Counties, Arkansas; (l) Upper Peninsula, including Keweenaw, Houghton, Baraga, Ontonagon, and Gogebic Counties, Michigan; and (m) Fulton County, Georgia (Brown \& Black, 2005). 
Across these 13 sites, households were selected using the list-assisted random-digitdialing, and one respondent was randomly selected in each eligible (with adult aged 50 or more) household. The mode of data collection was computer-assisted telephone interview (CATI), and the response rate averaged $63.0 \%$ across the 13 sites. Except Fulton County, the overall target for all other counties was 400 interviews. The overall target was increased to 550 interviews in Fulton County, with 350 allocated to South Fulton County and 200 to the rest of Fulton County (Brown \& Black, 2005).

\section{Study Sample}

Out of 5,298 individuals, this study uses 4,940 individuals for the final analysis. Proxies ( $\mathrm{n}=176)$ were excluded from data analysis because they were not asked questions about participation in religious, social and family activities, which constitutes the dependent variable for this study. Second, 358 individuals were eliminated from the final analysis due to the vagueness of various categories of the variable employment status. Initially employment status was categorized as full-time, part time, not working, retired, homemaker and disabled. For the purposes of conceptual clarity and for conducting hierarchal multilevel modeling, only four categories full-time, part-time, not working and retired were taken into consideration.

\section{Measures}

A 108-item questionnaire was utilized to collect data in the 2002 CPOA study. Items on the questionnaire addressed social engagement, health status, problems with activities of everyday life, health insurance coverage, hospital stays, living arrangements, social activities, support from family and friends, access to transportation, demographic 
characteristics, and supportive, long-term services available in the community (Brown \& Black, 2005). In this study, 25-items were used in the analyses.

\section{Study Design}

This study used secondary data from the 2002 CPOA survey. A cross-sectional study design was used to examine which personal factors predict social engagement among community-dwelling older adults and whether knowledge of available services enhances social engagement among this population. Although this study uses social engagement as the dependent variable, researchers in the past have been used it as an independent variable predicting physical function and well-being among older adults (Caro \& Bass, 1995; Doty et al., 1998; Herzog et al. 2002; Johnson \& LoSasso, 2000; Martinson \& Minkler, 2006; Mjelde-Mossey \& Chi, 2004; Stevens-Ratchford \& Cebulak, 2004; Szafran, 2000; West et al., 1996) These studies suggested the importance of participation in productive, consumptive and regenerative activities among older adults.

\section{Dependent Variables}

In this study, older adults' self-identified their levels of social engagement by looking at various activities they had performed in the past week. These activities were classified into following three categories: religious activities (in the church or other worship activities); social activities (participation in a social activity such as watching a

movie, play, concert, going to a restaurant, sporting event, club meeting, etc.) and family activities (in the past week, got together with friends, neighbors and family). For the purposes of this study, the researcher combined all the three activities into one measure. Therefore, social engagement, which is a composite variable of three different activities, is looking at consumptive activities performed by older adults. The researcher also 
performed analyses to see the effect of the independent variables on each kind of activity separately.

Social engagement is a count variable, which is measured on a scale ranging from (0) no engagement to (3) engagement in all activities. Participation in religious activities is a binary measure. Responses were coded (1) yes and (0) no. Participation in social activities is a binary measure too. Responses were coded (1) yes and (0) no. Similarly, Participation in family activities is a binary measure. Responses were coded (1) yes and (0) no.

\section{Independent Variables}

Two sets of independent variables are identified to explain the antecedents of engagement among older adults. Personal and situational factors predict productive occupations, productive engagement and volunteering in later life (Chambre, 1984; Caro \& Bass, 1995; Fisher et al., 1991; Fisher \& Schaffer, 1993; Gallagher 1994; Herzog \& Morgan, 1993; Hinterlong et al., 2001; Hinterlong, 2006; Lammers, 1991; Marriott Senior Living Services, 1991; Omoto \& Synder, 1995; Penner \& Finkelstein, 1998; Stevens-Ratchford \& Diaz, 2003). This study tested whether the following personal and situational factors influence social engagement: (a) gender, (b) marital status, (c) income, (d) educational attainment, (e) employment status, (f) health, (g) number of living children, (h) length of stay in community, (i) someone to take care of me in case of an emergency, and (j) age.

Gender is coded male (0) and female (1). Age is coded (0) less than 65 years old, (1) 65 to 74 years old, (2) 75 to 84 years old, and (3) 85 and older. Health status is respondent's assessment of his/her general health and was measured ranging from $0=$ poor 
and 4=excellent. Marital status is coded married (1) and nonmarried (0). Education is measured on a scale, where (0) is less than high school, (1) is high school/GED, (2) is some college, (4) college degree (four years), and (5) is an advanced degree. Employment status is coded (0) retired, (1) not employed, (2) part time employment, and (3) full time employment. Number of living children was measured on a scale ranging from (0) zero children to (4) four or more children. Annual income was measured on a scale ranging from (0) less than $\$ 10,000$ to (7) $\$ 100,000$ and more. Having someone (other than police and emergency service) in an emergency was measured (0) no and (1) yes. Length of stay in community is measured on a scale ranging from (0) less than 2 years to (4) more than 20 years.

The study included four community level factors as independent predictors of social engagement. They are: (a) knowledge of available services, (b) perception of community as a place to live, (c) perception of older adults about being influential in making their community a better place to live, and (d) perceptions of older adults about local officials taking into account interest and concerns of older adults. Knowledge of available services is a count variable of 12 different services in a community (senior center, adult day program, housekeeping services, senior lunch programs, telephone helpline, home repair assistance, visiting nurse service, personal assistance, door-to-door transportation, nursing home, assisted living facility and hospice care).

Knowledge of available services is measured on a scale from (0) no service available to (12) availability of all services. Rating of community as a place to live was measured on a scale ranging from (0) poor to (4) excellent. Perception of influence in making community a better place to live was measured on a scale ranging from $(0)$ none 
to (4) a lot. Similarly, perception of whether local officials take into account interests and concerns of older adults was measured on a scale ranging from (0) none to (4) a lot.

\section{Data Analyses Plan}

All the variables in the analysis were screened for missing data and normality. Missing values were identified and assessed for randomness. Other than data missing due to proxy interviews, all other missing data was random in nature. In order to use Hierarchal Linear and Nonlinear Modeling it was necessary to eliminate all cases with missing data for one or more variables. Further, the variables were also screened for measures of skewness and kurtosis. Histograms supported assessment of skewness. There were no instances found concerning violations of normality.

\section{Bivariate Analyses}

One-way ANOVAs were computed to assess whether there were any significant group differences in mean social engagement scores for the ordinal predictors in this study. A Tukey's Honestly Significant Difference (HSD) test was requested to compare significant group differences for social engagement and $\mathrm{R}^{2}$ was utilized to assess the effect size of results. Further, in order to examine potential differences for various levels of social engagement for nominal-level variables, $t$-tests statistics were calculated.

\section{Measures of Association}

The direction and strength of relationship between various variables was explored using the Pearson's correlation. Results of multivariate analysis depend on measures of association and to avoid possible bias in results all measures were examined for multicollinearity, that is, correlation between predictors $\geq .70$ (Cortina, 1993). No instances of multicollinearity were found between measures. 


\section{Multilevel Modeling}

This study collected data from individuals who were nested within 13

communities across 10 states in the U.S. Therefore, the data for this study are hierarchical in nature. The most appropriate method of data-analysis is hierarchical linear modeling (HLM; Bryk \& Raudenbush, 1992). Hence, hierarchal linear modeling was used to examine the association of demographic and community-level variables with social engagement.

Multilevel modeling techniques such as HLM offer a number of advantages over traditional techniques such as ANOVA and regression (Beaubien, Hamman, Holt, \& Boehm-Davis, 2001). First, error terms are not systematically biased because HLM separates out criterion variance into within and between components. That is, HLM makes it possible to determine how much variance is explained by characteristics of individual and community. This leads to more accurate effect size estimates and standard errors. Second, meaningful variance is not wasted because HLM uses all available information. Finally, testing of cross-level effects becomes feasible while using HLM (Beaubien et al., 2001). An example of a cross-level effect is how the relationship between gender (level 1) and social engagement (dependent variable) vary by community (level 2).

The outcome of social engagement was treated as an interval-level measure. Hierarchical Linear Modeling option of the HLM6 software was used for analysis (Raudenbush, Bryk, \& Congdon, 2004). In the hierarchical linear model social engagement was the dependent variable with a response at four levels $(0=$ no engagement, $1=$ engagement in one activity, $2=$ engagement in two activities and $3=$ engagement in all 
three activities). At level 1, predictors were entered into the regression equation in a hierarchical fashion, individual characteristics first, community factors second and knowledge of supportive services third. The independent variables were added in steps to check their effects on the model. Demographic information for the respondents was entered in the first model. Age, marital status, educational attainment, length of stay in community, some social support, gender, income, employment status, and health are the main demographic variables used. The community-level variables along with the knowledge of supportive services were added in a subsequent model to observe the mediator effect of these variables. In the hierarchical linear model, level 2 consisted of 13 different communities.

Assuming multivariate normality, full maximum likelihood estimation procedure was used for this outcome to estimate the means and covariance matrices. Repeated imputation-estimation cycles were conducted until the model no longer significantly improved with additional cycles. This study utilized nested models and all predictors were entered as fixed effects. Using the -2 log-likelihood ratio (i.e., deviance) test these nested models were compared to determine whether the model with more parameters fit the data better than the simpler model. One more benefit of using full maximum likelihood for parameter estimation is that model fit statistics are available for model comparison (Bryk \& Raudenbush, 1992).

The other three outcome measures (participation in religious, social and family activities) were analyzed using the Hierarchical Generalized Linear Modeling (HGLM) module of the HLM6 software. All the three outcomes were dichotomous and therefore analyzed as Bernoulli models (Dunteman \& Ho, 2006) using full penalized quasi- 
likelihood (full PQL) estimation, which unfortunately does not produce model fit statistics (Bryk \& Raudenbush, 1992). Therefore, it was not possible to use deviance test to determine whether adding more parameters increased the model fit for the HGLM analyses. Similar to the HLM models, the HGLM models were nested and parameters were added subsequently as fixed effects. All HGLM results are unit-specific and these results hold constant the random effects for the three outcomes (Bryk \& Raudenbush, 1992). 


\section{Chapter 4: Results}

Chapter one of this dissertation established the need to determine the set of personal characteristics and community level factors along with presence of various supportive services that predict social engagement among community-dwelling older adults. Chapter two focused on the literature related to the characteristics of older adults participating in various forms of social, family and religious activities. Chapter three described the method and procedures used to determine which set of personal characteristics, community level factors and knowledge of various supportive services best predicts social engagement among community-dwelling older adults. This chapter describes the sample of older adults who participated in the CPOA survey of 2002 and presents the results of hierarchical multilevel modeling analyses that show which combination of older adult's personal characteristics, community level factors and knowledge of supportive services predicts social engagement.

\section{Target Population}

Mathematica Policy Research (MPR) was chosen by the Robert Wood Johnson Foundation to conduct the CPOA Survey for evaluating 13 grantee communities. In each of the grantee communities, between 343 and 521 residents, 50 years of age or older were interviewed. Respondents were identified through a random-digit dialing (RDD) sampling methodology, with the telephone numbers generated by a vendor specializing in such samples. The telephone survey process continued for 20 weeks, and data were collected from 5,298 individuals age 50 years of age or older living in 13 participating sites. The eligibility rate for all sites combined was $27 \%$ and varied across sites from 19 
to $45 \%$ (Brown \& Black, 2005). The results in Table 1.1 contains the final sample sizes and response rates for the grantee communities in addition to their geographical areas, while the results in Table 1.2 contains distribution of this study's sub-sample across 13 sites.

Insert Tables $1.1 \& 1.2$ about here

Characteristics of Participants

The study sample $(\mathrm{N}=4940)$ included more females $(61.1 \%)$ than males $(38.9 \%)$. Slightly more than half (50.4\%) of the participants were younger than 65 years of age; $24.3 \%$ of participants were between 65 and 74 years of age, 19.8\% were between 75 and 85 years of age, and $5.5 \%$ of the participants were 85 years of age or older. Further, nearly $40 \%$ of participants were employed part-time (10.2\%) or full-time (29.4\%). Only $36.4 \%$ participants made more than $\$ 40,000$ a year. Most participants $(76.3 \%)$ in this study reported were either in good (28.5\%), very good (27.6\%), or excellent (20.2\%) health, and only $47 \%$ were married. Only a small proportion (14.2\%) of participants had no child. In terms of the educational attainment, almost $49 \%$ of older adults had some college or more. Further, most of the older participants $(82.4 \%)$ reported that they had someone other than the police and emergency services to take care of them in the case of an emergency.

\section{Characteristics of Communities}

In addition to knowledge about the availability of various supportive services within the community, the participants shared their perspectives on the living situation in their respective communities. Most of the respondents (73.6\%) had lived in the same community for more than 20 years and $81.7 \%$ reported that their community was a 
"good" or "excellent" place to live. There was a significant proportion of older adults (68.5\%) who thought that they could have influence in making their community a better place to live. Similarly, nearly $68 \%$ older adults reported that local officials take into account the interests and concerns of older people in their community.

Older adults were also asked questions regarding the knowledge of 12 supportive and long-term care services available in their area. Those include: (a) presence of senior center, (b) adult day program, (c) telephone helpline, (d) housekeeping service, (e) senior lunch program, (f) home repair assistance, (g) visiting nurse service, 9h) personal assistance, (i) door-to-door transportation, (j) assisted living facility, and (k) nursing home. For the purposes of conducting multilevel modeling, knowledge of the 12 services was combined into a single continuous variable. Very few participants $(1.7 \%)$ reported having no knowledge of the available supportive services in the community, whereas nearly $83 \%$ of participants were aware of six or more services in their area. Only a small proportion of participants $(8.7 \%)$ reported no social engagement. However, $21.2 \%$ of older adults participated in one of the activities; $40.4 \%$ participated in two activities, and 29.6\% participated in all the three activities. The results in Table 3 show the scales, means, standard deviations and inter-correlations of all variables in this study.

Insert Tables $2 \& 3$ about here

Bivariate Analyses

One-way analyses of variance (ANOVAs) were computed to assess the extent to which there were any significant differences in mean social engagement scores for all ordinal predictors. A Tukey's HSD test was conducted to test for significant group differences for social engagement and $\mathrm{R}^{2}$ was utilized to assess the effect size of results. 
There were significant differences in mean ratings on levels of social engagement for age, education, employment status, health, number of living children, income, rating of community, perceptions of older adults in making their community a better place to live, interest of official officials, and knowledge of services available. There were no statistically significant differences in the mean length of stay in a community for various levels of social engagement. Those results are shown in Table 4 .

Insert Table 4 about here

In order to examine potential mean score differences in social engagement for dichotomous variables, $t$-tests statistics were calculated. Females were significantly more likely than males to socially engage. Similarly, married older adults were statistically more likely than non-married older adults to socially engage, as were those who had someone to call in the case of emergency. Those results are shown in Table 5.

Insert Table 5 about here

To determine the magnitude and nature of association between variables included in the multilevel analyses, a correlation matrix was computed. Almost all the independent variables were significantly correlated with each other (see Table 3 ). However, the magnitude of the associations were small to medium; hence, no instances of multicollinearity were identified.

\section{Predicting Social Engagement}

HLM 6 was used to test the research hypotheses. Participants with no missing data were considered for the purpose of data analysis ( $\mathrm{N}=3541)$. At Level 1, three types of predictors were entered into the regression equation in a hierarchical fashion: 1) individual characteristics, 2) community factors, and then 3) knowledge of supportive 
services. Level 2 consisted of the 13 communities from which the samples were drawn. Table 6 provides a summary of the fixed and random effects in the nested hierarchical multilevel models. The HLM coefficients for each parameter represent the magnitude and direction of the effect that a one-unit change in the predictor has on the outcome. Research Question 1

In the final model (Model 3), all of the variables were entered as predictors of social engagement. In this model, gender, educational attainment, health status, number of living children, income, having someone to call in case of emergency, ability to influence the community and knowledge of available services were associated with higher social engagement scores $(p<.05)$. However, employment status was significantly negatively associated with levels of social engagement. The direction of relationship between employment status and social engagement is based on how employment status is coded $(0=$ retired; $1=$ not working; $2=$ part time; and $3=$ full time). Contrary to alternative hypotheses, this study found no evidence of differences in social engagement by age, length of stay in community, believing that local officials are concerned about the needs of older adults or rating of a community.

The social engagement score for women was 0.16 points higher than for men. For each additional living child, the social engagement score was .07 points higher. Having someone to call in case of emergency also increased the average number of social engagement activities by 0.18 points.

\section{Research Question 2}

Model 1 consisted of individual factors. Model 2 tested the hypothesis that addition of community perceptions and knowledge of services would reduce or eliminate 
the magnitude of relationship between individual factors and social engagement found in Model 1. However, when community perception variables were added in Model 2 the same pattern of statistical significance from Model 1 remained. Furthermore, perceiving that local officials take into account the interests and concerns of older people in their community increased the mean social engagement score. Model comparison tests revealed that the addition of community perception predictors to individual factors improved the model fit, $\chi^{2}(3, \mathrm{~N}=3541)=38.25, p<.001$.

In Model 3, knowledge of services available in the community was added to see if that predictor mediated the relationship between individual factors and the outcome of social engagement. In this final model, all previously significant individual factors (see Model 1) were still statistically significant except for length of residence in community. Further, perception regarding local officials' considerations of needs and concerns of older adults was no longer a statistically significant predictor of social engagement. For each additional service that older adults knew was available in the community, the predicted mean score for social engagement was .04 points higher. The model comparison test statistic suggests that Model 3 is a statistically significant better fit than Model 2, $\chi^{2}(1, \mathrm{~N}=3541)=46.35, p<.001$.

Insert Table 6 about here Predicting Participation in Religious Activities

HLM 6 was used to determine which set of individual and community level factors along with knowledge of supportive services predicted participation in religious activities among participants $(\mathrm{N}=3,341)$. In the hierarchical generalized linear model, participation in religious activities was the dependent variable with a binary response 
( $0=$ no, $1=$ yes). At level 1 , three types of predictors were entered into the regression equation in a hierarchical fashion and level 2 consisted of 13 different communities. Table 7 provides a summary of the nested hierarchical generalized linear models predicting participation in religious activities and the data provided in the table are unitspecific fixed and random effects of predictors on the outcome.

Research question 1 asked what all factors predict risk of participation in religious activities. Model 1 consisted of individual factors as predictors of religious participation. In addition to individual factors, model 2 consisted of perceptions of community as predictors of religious participation. Similarly, model 3 consisted of knowledge of services variable as predictor of religious participation. The odds ratios for religious participation are presented in Table 7. A statistically significant odds ratio greater than 1 indicates that the predictor increases the odds of participation in religious activities, while an odds ratio less than 1 indicates that the predictor reduces the likelihood of religious participation.

\section{Research Question 1}

In Model 3, after entering all predictors, the expected odds of participation in religious activities increased by $14 \%$ (computed by subtracting the odds ratio of 1.14 from 1) for each additional year of age above the sample average. Being a female increased the odds of participation in religious activities by $57 \%$. Similarly, being married increased the odds by $36 \%$, having higher education increased the odds by $9 \%$, good health increased the odds by $14 \%$, each additional child increased the odds by $12 \%$, each additional year of living in the community increased the odds by $13 \%$, believing in one's ability to influence the community increased the odds by $20 \%$ and knowledge of 
services available increased the odds of participation in religious activities by $5 \%$.

However, having higher income decreased the odds of participation in religious activities by $7 \%$ (computed by subtracting the odds ratio of 0.93 from 1 ). Contrary to alternative hypotheses, this study found no evidence of differences in the participation of religious activities by employment status, having someone to call in case of emergency, or believing that local officials are concerned about the needs of older adults or rating of a community.

\section{Research Question 2}

This study hypothesized that both community perceptions and knowledge of services will reduce or eliminate the magnitude of the relationship between individual factors and participation in religious activities. However, this was not the case. Addition of community perception variables as predictors in Model 2 and knowledge of services as a predictor in Model 3 did not reduce the magnitude of relationship between individual factors and participation in religious activities.

Insert Table 7 about here

\section{Predicting Participation in Social Activities}

HLM 6 was used to determine which set of individual and community level factors along with knowledge of supportive services predicted participation is social activities among participants $(\mathrm{N}=3,341)$. In the hierarchical generalized linear model, participation in social activities was the dependent variable with a binary response $(0=\mathrm{no}$, 1=yes). Research question 1 asked what all factors predict risk of participation in social activities. Model 1 consisted of individual factors as predictors of social participation. In addition to individual factors, model 2 consisted of perceptions of community as 
predictors of social participation. Similarly, model 3 consisted of knowledge of services variable as predictor of social participation. Table 8 presents the odds ratios for the outcome of social participation. While holding constant all the predictors in the model, the odds ratios represent the amount of change in the predicted odds of social participation associated with a one-unit change in the independent variable to the predicted odds without that one-unit change in the predictor.

\section{Research Question 1}

In the final model, the expected odds of participation in social activities increased by $29 \%$ (computed by subtracting the odds ratio of 1.29 from 1 ) for every one year of education more than the sample average. Being in good health increased the odds of participation in social activities by $19 \%$. Similarly, each additional child increased the odds by $11 \%$, having someone to call in case of emergency increased the odds by $32 \%$, ability to influence the community increased the odds by $10 \%$, believing that local officials are concerned about the needs of older adults increased the odds by $11 \%$, and knowledge of services available increased the odds of participation in social activities by $7 \%$. Contrary to alternative hypotheses, this study found no evidence of differences in the participation of social activities by age, gender, marital status, employment status, length of residence in community, or rating of a community.

\section{Research Question 2}

This study hypothesized that both community perceptions and knowledge of services will reduce or eliminate the magnitude of the relationship between individual factors and participation in social activities. However, this was not the case. Addition of community perception variables as predictors in Model 2 and knowledge of services as a 
predictor in Model 3 did not reduce the magnitude of relationship between individual factors and participation in social activities.

Insert Table 8 about here

Predictors of Participation in Family Activities

\section{Research Question 1}

In Model 3, the expected odds of participation in family activities increased by $15 \%$ (computed by subtracting the odds ratio of 1.15 from 1 ) for every one year of education more than the sample average. Being a female increased the odds of participation in family activities by $31 \%$. Similarly, good health increased the odds by $21 \%$, each additional living child increased the odds by $15 \%$, having someone to call in case of emergency increased the odds by $74 \%$, and knowledge of services available increased the odds of participation in family activities by $8 \%$. However, being employed

decreased the odds of participation in family activities by $12 \%$ (computed by subtracting the odds ratio of 0.88 from 1) and being married decreased the odds by $19 \%$. Contrary to alternative hypotheses, this study found no evidence of differences in the participation of family activities by age, length of residence in community, rating of a community, ability to influence community or believing that local officials are concerned about the needs of older adults.

\section{Research Question 2}

Contrary to expectations, this study did not find any support for the hypotheses that community perceptions and knowledge of services would reduce or eliminate the magnitude of the relationship between individual factors and participation in family activities. However, knowledge of services mediated the relationship between the 
community perception variable about perceiving that local officials are concerned about needs of older adults and family engagement: with knowledge of services in the model, perceptions about local officials is no longer statistically significant.

Insert Table 9 about here 


\section{Chapter 5: Discussion}

The final chapter summarizes key findings of the study, presents conclusions drawn from the findings, and outlines implications for future policy, practice and research. The first section summarizes the key findings related to the personal and community characteristics that predict social engagement among community-dwelling older adults. The second section presents discussion and conclusions about communitydwelling older adults' individual resources, their perceptions about community characteristics and knowledge of services available, which are helpful in assisting older adults to socially engage. The third section provides policy, practice and research implications for ensuring provision of appropriate services for older adults' to socially engage. Finally, the chapter concludes with considerations for future research.

\section{Summary of Key Findings}

Out of 5,298 individuals, this study uses 4,940 individuals for the final analysis. A 108-item questionnaire was utilized to collect data in the 2002 CPOA study. In this study, 25-items were used in the analyses. The results of the study are summarized in the following four key findings:

1. In the week prior to participating in this study, nearly all the participants were socially engaged in at least one of the three activities, in a week prior to participating in this study.

2. Individual characteristics that significantly impact social engagement were: being female, higher education, working less hours or being retired, better health, having more living children, higher income, and having someone to call 
in case of emergency. Characteristics which were not found to impact social engagement were: age and marital status. Length of stay in the community was not significant when knowledge of supportive services was added to the regression model.

3. External variables found to be significant predictors of engagement were: belief in ability to help make the community a better place to live, and knowledge of a greater number of supportive services available in the community. Variables which were not significant in this study were: rating of community as a place to live. Interest of local officials about needs and concerns of the older adults was no longer a significant predictor when knowledge of supportive services was added to the regression model.

4. In this study, impacts of individual and community factors varied by the type of activity.

a. Engagement in religious activities was associated with higher education, lower income, better health, being married, older age, longer length of time living in the community, greater number of children, being female, believing in one's ability to influence the community, and knowledge about greater number of services. Engagement in religious activities was not associated with employment status, having someone to call in case of emergency, one's rating of the community, or by perception about interest of local officials taking into consideration needs and concerns of the older adults. 
b. Engagement in social activities was found to be associated with higher education, better health, having more children, higher income, having someone to call in case of emergency, and greater belief in ability to help make the community a better place to live. Engagement in social activities was not associated with age, gender, marital status, employment status, length of stay in community, and rating of community as a place to live.

c. Engagement in family activities was associated with higher education, better health, being female, working less hours, having more children, having someone to call in case of emergency, being unmarried, higher income, and knowledge about more services available in the community. Engagement in family activities was not significantly related to age, length of stay in community, rating of community, influence in making community a better place to live, and interest of local officials about needs and concerns of the older adults.

\section{Discussion}

Based on CPOA data of community-dwelling older adults in the U.S., this study identifies factors associated with their social engagement. The study results indicate that social engagement is influenced by both the person involved in the process and also their knowledge and perceptions of their community. Based on resource dependency theory, the findings support the key concepts of particularism and concreteness. In turn, the results support the assertion that older adults shape their own environment while 
participating in various activities and are also influenced by various resources present in the community.

\section{Individual Characteristics}

Current literature suggest that individual characteristics influence social engagement, which is consistent with results in this study (Antonucci, 1990; Chen \& Fu, 2008; Fisher et al., 1991; Herzog, Ofstedal, et al., 2002; Hill, 1985; Marriott Senior Living Services, 1991). In contrast with other research (Chambre, 1993; Fisher et al., 1991; Chen, \& Fu, 2008; Herzog \& Morgan, 1993), the results indicate that neither age nor marital status is a significant predictor of social engagement. The results in one study show that age has a significant effect on social engagement (Chen, \& Fu, 2008). Some have suggested that the effect of age may have slowly dissipated as the workforce participation of older adults has increased (Harvard School of Public Health/Metlife Foundation, 2004; Seongsu \& Feldman, 2000). It may also be because Baby Boomers have been less engaged in civic activities than their parents (Harvard School of Public Health/Metlife Foundation, 2004; Seongsu \& Feldman, 2000).

Similarly, there are few studies in which the results suggests that marital status is an important factor and a few that suggest that marital status is not significantly associated with volunteering (Chambre, 1993; Fisher et al., 1991; Herzog \& Morgan, 1993). Therefore, the literature about the relationship between engagement and marital status is divided. The findings of the current study are also mixed as marital status was predictive of social engagement, religious participation, and family activities, but not social activities. 
Consistent with previous research, gender predicts social engagement in this study. Some experts have suggested that differences due to gender are associated with the type of service or chosen activity (Antonucci, 1990; Chen \& Fu, 2008; Fisher et al., 1991; Herzog, Ofstedal, et al., 2002; Hill, 1985; Marriott Senior Living Services, 1991). Regardless of the activity, women who participated in this study were more socially engaged. The results in this study support the notion that having someone to call in case of emergency leads to increased social engagement (Chen \& Fu, 2008; Litwin, 2000).

Also consistent with results in previous studies, health was a significant predictor of social engagement in this study (Chen \& Fu, 2008; Fischer et al., 1991; Herzog \& Morgan, 1993; Herzog, Ofstedal, et al., 2002; Ross \& Mirowsky, 1995). Good health among older adults increases an individual's social engagement, though it is unknown the extent to which health is a predictor of engagement or engagement is a predictor of health. However, the results in some studies that show that participation in various social, leisure, and productive activities increases physical function and well-being (Bambrick \& Bonder, 2005; Bukov et al., 2002; Herzog, Ofstedal, et al., 2002; Menec, 2003; Rozario et al., 2004; Stevens-Ratchford \& Cebulak, 2004; Wahrendorf et al., 2006).

As the results in previous studies show, education, income, and retirement were significant predictors of social engagement in this study as well (Chambre, 1993; Chen \& Fu, 2008; Fischer et al., 1991; Herzog \& Morgan, 1993; Herzog, Ofstedal, et al., 2002; Ross \& Mirowsky, 1995). This may be because of higher level of awareness, more leisure time on hand, and ability to cover extra costs associated with engagement in various religious, social, and family activities. 
The results of this study suggest that, in comparison to older adults who have no children, parents with one or more living children engage and participate more in religious, social, and family activities significantly more often. The results in previous studies are mixed with regard to this characteristic and indicate that older adults who have no children are more likely to seek companionship with friends and relatives, go to public places, and travel just as frequently as older adults who have children and go on outings more frequently than those older adults who have children (Connidis, 1992).

Finally, length of stay in the community was also a significant predictor of social engagement in this study, although this factor was less important when knowledge of supportive services was added to the model. This suggests that duration of stay in a community is important for social engagement. However, it highlights the need for future research to examine the effects of having knowledge and information about supportive services on various aspects of social engagement.

\section{External Facilitators}

Herzog, Ofstedal and colleagues (2002) highlighted that although individual characteristics affect activities, the impact of external facilitators and constraints needs to be examined as well. Two such variables, i.e., older adults' influence in making their community a better place to live and knowledge of supportive services were significant predictors of social engagement. This suggests that older adults may like the opportunity to make their community a better place to live, which will also be an avenue for them to engage socially. Given the limited research in this area, this study is distinctive in establishing the relationship between social engagement and older adults' perception of influence on their community. 
Equally important were the external variables that were not statistically significant in this study. More than three-fourths of the older adults in this study rated their community as a "good" or "excellent" place to live. Although the researcher expected that this factor would significantly predict social engagement given that higher satisfaction with the residence likely leads to higher involvement in later life. However, this was not the case. Further, more than half of the older adults in this study thought that local officials do take into account needs and concerns of older adults in their area. Although the hypothesis that a community where local officials are proactive in considering needs of the older adults may provide better opportunity for enhancing social engagement, this was not a significant predictor of social engagement when knowledge of supportive services was added in the model. This suggests that knowledge of available services nullified the effects of whether local officials took into consideration needs of the older adults.

Factors Associated with Participation in Religious, Family, and Social Activities Herzog, Ofstedal and colleagues (2002) mentioned that predictors vary by activities. Similar to predicting social engagement, knowledge of services was a significant predictor of participation in religious, social and family activities. The results in this study such as age and length of stay in the community were significantly associated with participation in religious activities. This suggests that the longer individuals stay in a community, the stronger religious ties they develop. Similarly, marital status was significantly associated with participation in religious activities, which is consistent with results in previous studies (Taylor \& Chatters, 1991; Taylor, Chatters \& Jackson, 2007; Taylor, Chatters \& Levin, 1992). This indicates that marriage and being 
female are related to higher levels of religious participation. Furthermore, participation in religious activities was significantly predicted by older adults who thought they were influential in making their community a better place to live.

Education, better health, higher income, having more children, and having someone to call in case of emergency significantly predicted engagement in social activities. Additional predictors included older adults thinking that they were influential in making their community a better place to live and that the local officials in their community take into account needs and concerns of the older adults. Unlike results in previous studies, the results in this study suggest no evidence that gender influences engagement in social activities, specifically that older women dominate engagement in social activities (Antonucci, 1990; Herzog, Ofstedal et al., 2002; Hill, 1985).

All individual characteristics, except age and length of stay in community were significant predictors of engagement in family activities. The result in this study suggests that older adults felt comfortable engaging in family activities once they knew they had someone to call in case of emergency. When knowledge of services was taken into account, the interest of local officials no longer significantly predicted engagement in family activities. Similarly, employment status was negatively associated with engagement in family activities, which suggests that if older adults work, their engagement in family activities decreases.

Despite the beneficial findings from this study, there are inherent limitations associated with self-report and cross-sectional research. First, the direction of effects cannot be inferred. This cross-sectional analysis supports the main tenets of the conceptual model; however it is likely that social engagement also impact personal 
characteristics of older adults and their perceptions about the community. Future research needs to include longitudinal studies to better understand the underpinning causal structure of the person-environment-social engagement relationships. Despite these limitations, the results from this study coupled with theoretical and empirical approaches to personal and community factors, suggests that knowledge of available supportive services may facilitate older adults to participate in religious, social and family activities, which may result in greater social engagement over time.

\section{Conclusions}

Based on the findings in the study and the discussion of those findings several conclusions seem plausible. First, it appears that community and the relationships within the community are important inspite of individual differences among older adults. Second, it seems that older adults who like the community in which they reside and are familiar with their surroundings may promote successful aging, even when the community lacks opportunities that promote their social engagement. Third, it appears that duration of stay in a community is important for engaging older adults in various activities, though this is not a necessary condition for enhancing social engagement. Fourth, it seems likely that if we improve public relations and marketing of services available to older adults, they will engage in more social activities. Moreover, if the knowledge acquired through this study lays the foundation for the development of resources, supportive services, and polices, then we would promote participation in various religious, social, and family activities among community-dwelling older adults. Finally, the researcher advocates for developing more friendly communities and 
activities, as well as transferring information about the community resources to older persons, which could enhance their social engagement.

\section{Implications}

Individual and community factors need attention while designing models of engagement for older adults to enhance their physical and emotional health. In addition, consideration of particular subgroups of people is essential. Also, due to the likely differences in the environmental supports needed to promote social engagement among different subgroups, future policy and design interventions must be tailored towards the specific needs of the target populations. This knowledge has implications for several groups, including researchers, policymakers, educators, practioners, and communitydwelling older adults.

Policy

Policy at the national level is increasingly focusing on aging issues, and policy that financially empowers communities could be an answer to assuming responsibility for and meeting the needs of the older adults. Hence, at the state and community level, funding for partnership programs could be a way to improve and change services that better meet the needs of older adults and their families. Those programs could also be helpful in engaging and involving older adults by teaching and learning through the exchange of experiences between older adults and various community-based organizations. To further enhance social engagement among the older adults, policy makers could use this information to develop programs that would disseminate information about various community services to older adults. Finally, policymakers may want to consider funding for programs that take into account the individual characteristics 
and community circumstances when making decisions regarding social engagement of older adults.

\section{Practice}

Our society has experienced dramatic changes in the economy, in demographics, and in service delivery. This requires social workers and other related professionals to become active participants in community solutions for complex social problems. The growing trend in community practice is to focus on community capacity building, social/economic development, empowerment, and advocacy. Social workers have been effective in the provision of services that are provided by many community partnership organizations in the CPOA program (Bolda et al., 2005). Therefore, by becoming active participants in community partnerships, social workers could use their skills to implement and evaluate models and interventions that would work for the older adults, thus enhancing their involvement in later life.

Social workers could work towards improving quality of life and developing a service delivery system that is responsive to the needs of community-dwelling, older adults. Geriatric social workers serving as clinicians and advocates in various community-based organizations can utilize these findings to identify services that would best support social engagement activities among the older adults. In the end, social work practitioners will be able to advocate for older adults in the community, given their own increased awareness about predictors of social engagement and how they impact social engagement among the older adults.

\section{Research}


This initial study was completed to determine which set of personal and environmental characteristics predict social engagement for community-dwelling older adults. Similar studies should be conducted to assess various community level variables based on more than just the perceptions of older adults. Additional data should be obtained through various community assessment tools, such as, demographic data, attending community meetings or functions, surveying the community, interviewing key stakeholders, and focus groups. American FactFinder and State and County QuickFacts from U.S. Census data, as well as data in city and county planning offices also offer good resources to access a community's profile.

Because this research was limited to community-dwelling older adults living in their home in an urban and semi-urban setting, further research on older adults living in different environments such as rural areas, retirement communities, nursing homes and assisted living facilities seems needed. This may help researchers to identify environmental level variables different than those in larger population centers. Research that explores how knowledge of supportive services on social engagement affect recently relocated older adults who have not yet developed strong social ties with the community could be helpful. This would provide a new perspective about the importance of information for keeping older adults engaged. 


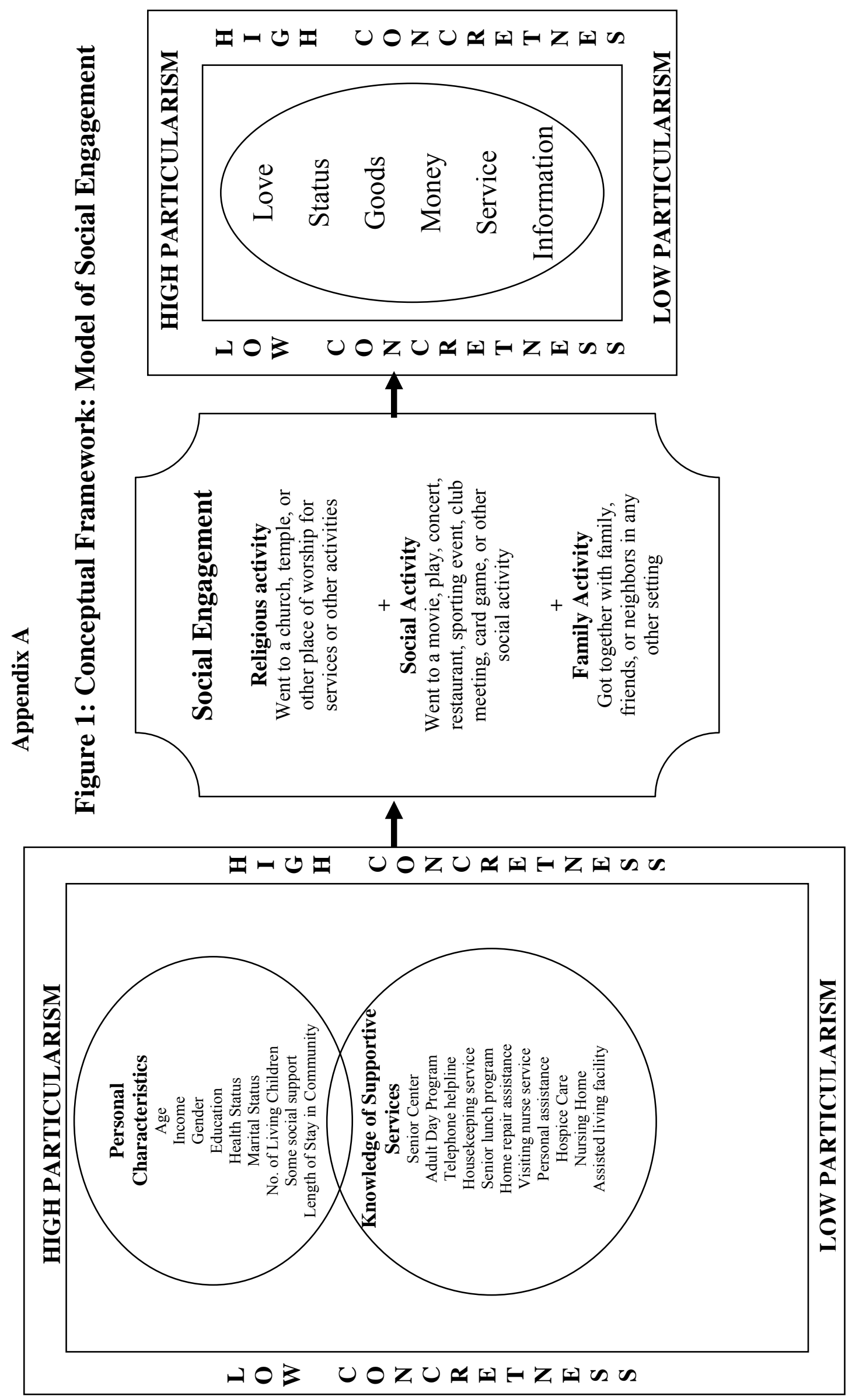




\section{Appendix B}

Table 1.1

Final Sample Sizes and Response Rates, By Site

\begin{tabular}{|c|c|c|}
\hline Community & $\begin{array}{c}\text { Final Sample } \\
\text { Size }\end{array}$ & $\begin{array}{c}\text { Response Rate } \\
\text { (Percent) }\end{array}$ \\
\hline Boston, MA & 384 & 56.5 \\
\hline Broome County, NY & 424 & 65.1 \\
\hline Chittenden and Grand Isle Counties, VT & 413 & 66.9 \\
\hline El Paso County, TX & 375 & 65.1 \\
\hline Harris County, TX & 455 & 55.9 \\
\hline Maui Island, HI & 379 & 70.8 \\
\hline Milwaukee County, WI & 378 & 66.8 \\
\hline Riverside County, CA & 370 & 62.8 \\
\hline St. Clair County, MI & 423 & 65.7 \\
\hline San Francisco County, CA & 343 & 52.6 \\
\hline Columbia and Union Counties, AR & 447 & 70.7 \\
\hline Upper Peninsula, MI & 386 & 66.0 \\
\hline Fulton County, GA & 521 & 53.6 \\
\hline Total & 5,298 & 63.0 \\
\hline
\end{tabular}

Source: Telephone survey of 5,298 individuals age 50 and older living in the 13 sites participating in the Robert Wood Johnson Foundation Community Partnerships for Older Adults Program. The survey was conducted by MPR in June-November 2002. 
Table 1.2

Distribution of Study Sample across 13 Sites

\begin{tabular}{|c|c|c|}
\hline Community & $\begin{array}{c}\text { Study Sample } \\
\text { Size }\end{array}$ & $\begin{array}{c}\% \\
\text { (Percent) }\end{array}$ \\
\hline Boston, MA & 363 & 7.3 \\
\hline Broome County, NY & 401 & 8.1 \\
\hline Chittenden and Grand Isle Counties, VT & 393 & 8.0 \\
\hline El Paso County, TX & 341 & 6.9 \\
\hline Harris County, TX & 421 & 8.5 \\
\hline Maui Island, HI & 344 & 7.0 \\
\hline Milwaukee County, WI & 358 & 7.2 \\
\hline Riverside County, CA & 347 & 7.0 \\
\hline St. Clair County, MI & 393 & 8.0 \\
\hline San Francisco County, CA & 319 & 6.5 \\
\hline Columbia and Union Counties, AR & 408 & 8.3 \\
\hline Upper Peninsula, MI & 366 & 7.4 \\
\hline Fulton County, GA & 486 & 9.8 \\
\hline Total & 4,940 & 100.0 \\
\hline
\end{tabular}


Table 2

Characteristics of the Participants

\begin{tabular}{|c|c|c|}
\hline Variable $(\mathrm{N})$ & Frequency & Percentage \\
\hline \multicolumn{3}{|l|}{ Gender (4919) } \\
\hline Male & 1913 & 38.9 \\
\hline Female & 3006 & 61.1 \\
\hline \multicolumn{3}{|l|}{ Age (4856) } \\
\hline Less than 65 & 2446 & 50.4 \\
\hline $65-74$ & 1182 & 24.3 \\
\hline $75-84$ & 962 & 19.8 \\
\hline 85 and older & 266 & 5.5 \\
\hline \multicolumn{3}{|c|}{ Health status (4835) } \\
\hline Poor & 300 & 6.2 \\
\hline Fair & 842 & 17.4 \\
\hline Good & 1380 & 28.5 \\
\hline Very Good & 1336 & 27.6 \\
\hline Excellent & 977 & 20.2 \\
\hline \multicolumn{3}{|c|}{ Marital status (4765) } \\
\hline Married & 2244 & 47.1 \\
\hline Not Married & 2521 & 52.9 \\
\hline
\end{tabular}

(Table 2, continued) 
Table 2 (continued)

\begin{tabular}{|c|c|c|}
\hline Variable $(\mathrm{N})$ & Frequency & Percentage \\
\hline \multicolumn{3}{|l|}{ Education (4750) } \\
\hline Less than high school & 902 & 19.0 \\
\hline High School diploma/GED & 1539 & 32.4 \\
\hline Some college & 1060 & 22.3 \\
\hline College degree (four years) & 708 & 14.9 \\
\hline Advanced degree & 541 & 11.4 \\
\hline \multicolumn{3}{|l|}{ Employment status (4778) } \\
\hline Full-time & 1407 & 29.4 \\
\hline Part-time & 488 & 10.2 \\
\hline Not employed & 1720 & 36.0 \\
\hline Retired & 1163 & 24.3 \\
\hline \multicolumn{3}{|l|}{ No. of living children (4916) } \\
\hline None & 699 & 14.2 \\
\hline One & 622 & 12.7 \\
\hline Two & 1333 & 27.1 \\
\hline Three & 959 & 19.5 \\
\hline 4 or more & 1303 & 26.5 \\
\hline \multicolumn{3}{|c|}{ Someone to take care of me (4932) } \\
\hline No & 867 & 17.6 \\
\hline Yes & 4065 & 82.4 \\
\hline
\end{tabular}

(Table 2, continued) 
Table 2 (continued)

\begin{tabular}{|c|c|c|}
\hline Variable $(\mathrm{N})$ & Frequency & Percentage \\
\hline \multicolumn{3}{|c|}{ Annual income $(\mathrm{N}=3656)$} \\
\hline$<10,000$ & 638 & 17.5 \\
\hline 10,000 to $<20,000$ & 715 & 19.6 \\
\hline 20,000 to $<30,000$ & 544 & 14.9 \\
\hline 30,000 to $<40,000$ & 415 & 11.4 \\
\hline 40,000 to $<50,000$ & 326 & 8.9 \\
\hline 50,000 to $<75,000$ & 460 & 12.6 \\
\hline 75,000 to $<100,000$ & 254 & 6.9 \\
\hline 100,000 and more & 304 & 8.3 \\
\hline \multicolumn{3}{|c|}{ Length of stay in community (4932) } \\
\hline$<2$ years & 102 & 2.1 \\
\hline 2 to 5 years & 290 & 5.9 \\
\hline 6 to 10 years & 290 & 5.9 \\
\hline 11 to 20 years & 618 & 12.5 \\
\hline$>20$ years & 3632 & 73.6 \\
\hline \multicolumn{3}{|c|}{ Rating of community (4893) } \\
\hline Poor & 189 & 3.9 \\
\hline Fair & 708 & 14.5 \\
\hline Good & 2085 & 42.6 \\
\hline Excellent & 1911 & 39.1 \\
\hline
\end{tabular}

(Table 2, continued) 
Table 2 (continued)

\begin{tabular}{|c|c|c|}
\hline Variable $(\mathrm{N})$ & Frequency & Percentage \\
\hline \multicolumn{3}{|c|}{ Influence on community (4929) } \\
\hline None & 457 & 9.3 \\
\hline Not very much & 1096 & 22.2 \\
\hline Somewhat & 1794 & 36.4 \\
\hline A lot & 1582 & 32.1 \\
\hline \multicolumn{3}{|c|}{ Interest of local officials (4927) } \\
\hline None & 509 & 10.3 \\
\hline Not very much & 1126 & 22.9 \\
\hline Somewhat & 2242 & 45.5 \\
\hline A lot & 1050 & 21.3 \\
\hline \multicolumn{3}{|c|}{ Social engagement (4910) } \\
\hline Zero & 427 & 8.7 \\
\hline One & 1043 & 21.2 \\
\hline Two & 1986 & 40.4 \\
\hline Three & 1454 & 29.6 \\
\hline \multicolumn{3}{|c|}{ Participation in religious activities (4910) } \\
\hline Yes & 2612 & 53.2 \\
\hline No & 2298 & 46.8 \\
\hline
\end{tabular}

(Table 2, continued) 
Table 2 (continued)

\begin{tabular}{|c|c|c|}
\hline Variable $(\mathrm{N})$ & Frequency & Percentage \\
\hline \multicolumn{3}{|c|}{ Participation in social activities (4910) } \\
\hline Yes & 2867 & 58.4 \\
\hline No & 2043 & 41.6 \\
\hline \multicolumn{3}{|c|}{ Participation in family activities (4910) } \\
\hline Yes & 3898 & 79.4 \\
\hline No & 1012 & 20.6 \\
\hline \multicolumn{3}{|c|}{ Knowledge of services available (4926) } \\
\hline Zero & 82 & 1.7 \\
\hline One & 77 & 1.6 \\
\hline Two & 96 & 1.9 \\
\hline Three & 165 & 3.3 \\
\hline Four & 172 & 3.5 \\
\hline Five & 267 & 5.4 \\
\hline Six & 306 & 6.2 \\
\hline Seven & 398 & 8.1 \\
\hline Eight & 553 & 11.2 \\
\hline Nine & 673 & 13.7 \\
\hline Ten & 722 & 14.7 \\
\hline Eleven & 815 & 16.5 \\
\hline Twelve & 600 & 12.2 \\
\hline
\end{tabular}

(Table 2, continued) 


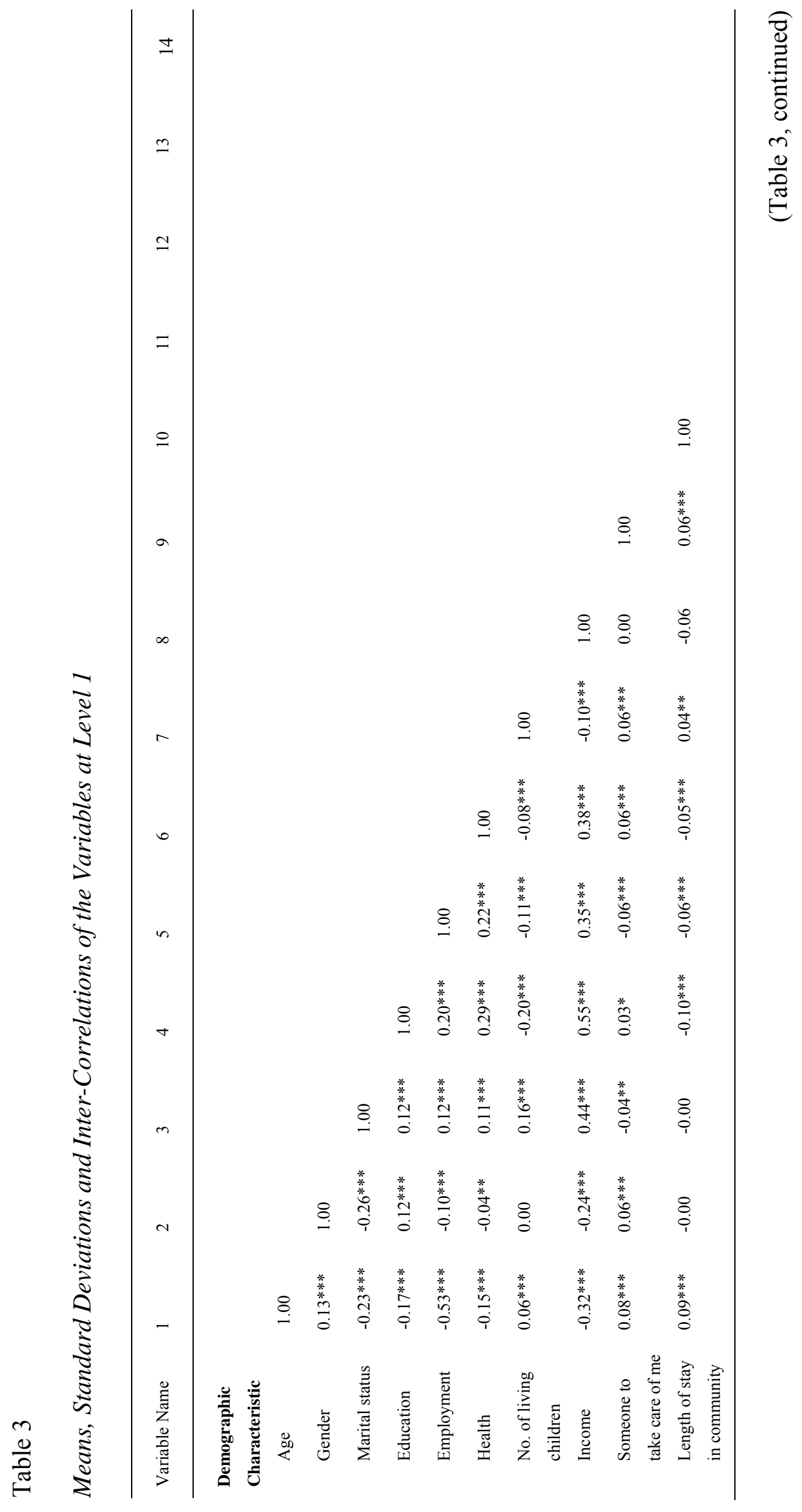




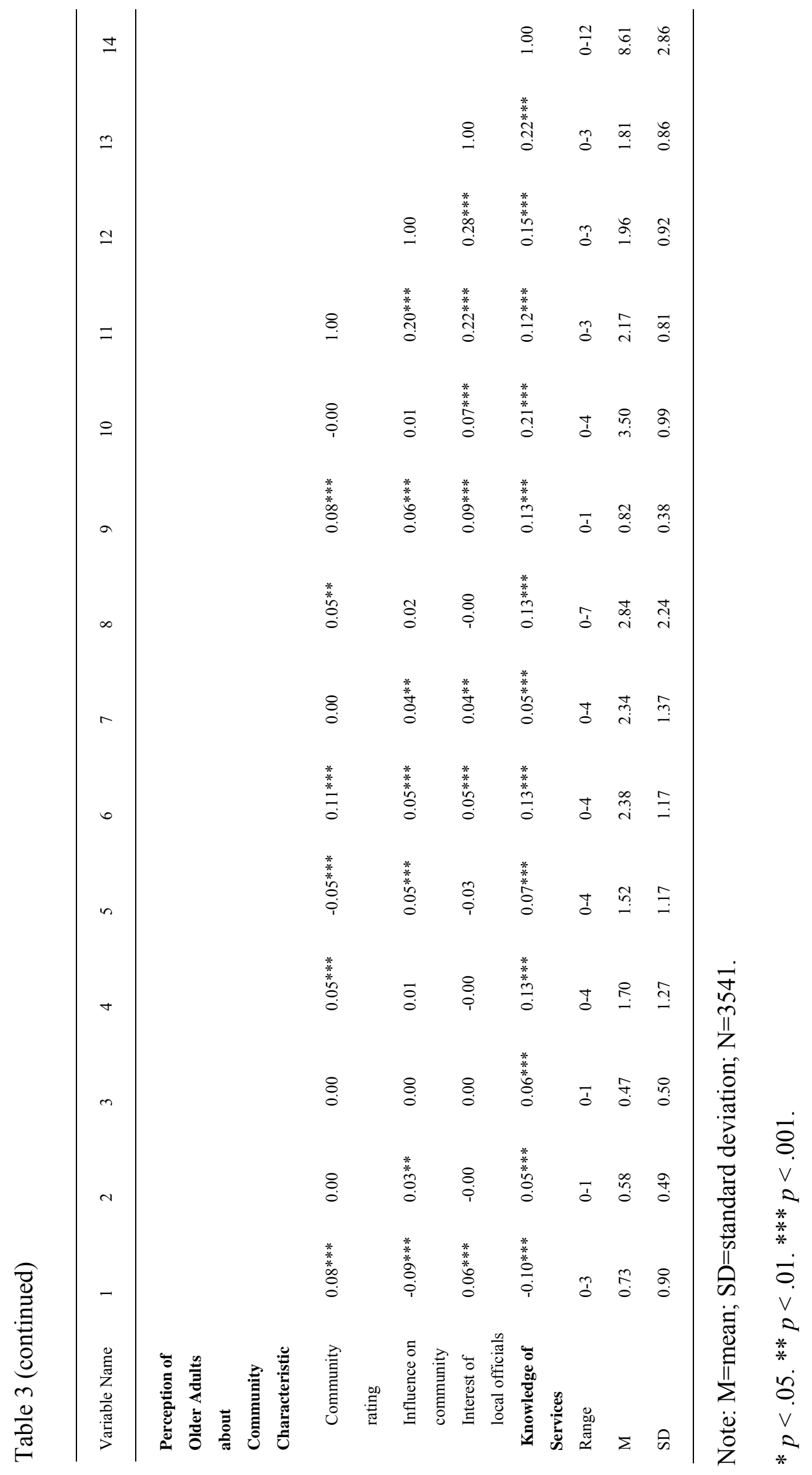


Table 4

Analysis of Variance for differences in Social Engagement

\begin{tabular}{|c|c|c|c|c|}
\hline Source & $d f$ & $F$ & Direction & $\mathrm{R}^{2}$ \\
\hline \multicolumn{5}{|c|}{ Individual Characteristics } \\
\hline Age & & $7.25 * * *$ & $0>1>2>3>4$ & 0.004 \\
\hline Between groups & 3 & & & \\
\hline Within groups & 4825 & & & \\
\hline Educational attainment & & $53.04 * * *$ & $4>3>2>1>0$ & 0.043 \\
\hline Between groups & 4 & & & \\
\hline Within groups & 4724 & & & \\
\hline Employment status & & $9.04 * * *$ & $2>3>0>1$ & 0.006 \\
\hline Between groups & 3 & & & \\
\hline Within groups & 4752 & & & \\
\hline Health & & $49.59 * * *$ & $3>4>2>1>0$ & 0.040 \\
\hline Between groups & 4 & & & \\
\hline Within groups & 4809 & & & \\
\hline No. of living children & & $12.69 * * *$ & $3>4>2>1>0$ & 0.010 \\
\hline Between groups & 4 & & & \\
\hline Within groups & 4888 & & & \\
\hline Income & & $23.59 * * *$ & $5>6>7>3>4>2>1>0$ & 0.043 \\
\hline Between groups & 7 & & & \\
\hline Within groups & 3638 & & & \\
\hline
\end{tabular}

(Table 4, continued) 
Table 4 (continued)

\begin{tabular}{|c|c|c|c|c|}
\hline Source & $d f$ & $F$ & Direction & $\mathrm{R}^{2}$ \\
\hline Length of stay in community & & 2.02 & $4>1>3>0>2$ & 0.002 \\
\hline Between groups & 4 & & & \\
\hline Within groups & 4905 & & & \\
\hline \multicolumn{5}{|l|}{ Perception of Older Adults } \\
\hline \multicolumn{5}{|l|}{ about Community } \\
\hline \multicolumn{5}{|l|}{ Characteristic } \\
\hline Community rating & & $3.65^{* *}$ & $3>2>1>0$ & 0.002 \\
\hline Between groups & 3 & & & \\
\hline Within groups & 4868 & & & \\
\hline Influence on community & & $31.15^{* * *}$ & $2>3>1>0$ & 0.019 \\
\hline Between groups & 3 & & & \\
\hline Within groups & 4904 & & & \\
\hline Interest of local officials & & $14.02 * * *$ & $2>3>1>0$ & 0.009 \\
\hline Between groups & 3 & & & \\
\hline Within groups & 4902 & & & \\
\hline \multirow[t]{2}{*}{ Knowledge of Services } & & $18.83 * * *$ & $12>11>10>9>8>7>$ & 0.044 \\
\hline & & & $6>5>4>3>2>1>0$ & \\
\hline Between groups & 12 & & & \\
\hline Within groups & 4890 & & & \\
\hline \multicolumn{5}{|c|}{ Note: The direction column indicates which group for the variable had higher mean value } \\
\hline \multicolumn{5}{|c|}{ for social engagement, and mean scores and deviations are presented in Table 3 . The last } \\
\hline \multicolumn{5}{|c|}{ column on the right highlights the small magnitude of the effects. } \\
\hline$<.05 . * * p$ & & & & \\
\hline
\end{tabular}


Table 5

T-Tests for differences in Social Engagement

\begin{tabular}{|c|c|c|c|c|}
\hline Variable & $N$ & $d f$ & $T$ & Mean (SD) \\
\hline \multicolumn{5}{|l|}{ Individual Characteristics } \\
\hline Gender & & 4894 & $-4.02 * * *$ & \\
\hline Male & 1901 & & & $1.84(0.92)$ \\
\hline Female & 2995 & & & $1.95(0.92)$ \\
\hline Marital status & & 4724 & $-5.19 * * *$ & \\
\hline Not married & 2508 & & & $1.85(0.94)$ \\
\hline Married & 2235 & & & $1.98(0.89)$ \\
\hline \multicolumn{2}{|l|}{ Someone to take care of } & 1198 & $-8.26 * * *$ & \\
\hline me & 864 & & & \\
\hline & & & & $1.66(0.98)$ \\
\hline No & 4046 & & & $1.96(0.90)$ \\
\hline Yes & & & & \\
\hline
\end{tabular}

$* p<.05 . * * p<.01 . * * * p<.001$. 
Table 6

Summary of Multilevel Modeling for Variables Predicting Older Adults

Social Engagement

Fixed Effects

Intercept
Model 1 Model 2 Model 3

$\begin{array}{lll}0.79 * * * & 0.61 * * * & 0.50 * * *\end{array}$

Demographic Characteristic

Age

0.00

0.00

0.01

Gender

$0.18^{* * *} \quad 0.18^{* * *}$

$(1=$ female $)$

Marital status ( $1=$ married $)$

0.01

0.02

0.02

Education

$0.10 * * *$

$0.10 * * *$

$0.09 * * *$

Employment

$-0.04 * *$

$-0.04 * *$

$-0.04 * *$

Health

$0.11 * * * \quad 0.10 * * * \quad 0.10 * * *$

Number of living children

$0.08 * * *$

$0.07 * * *$

$0.07 * * *$

Income

$0.05 * * *$

$0.05 * * *$

$0.05^{* * *}$

Someone to call in emergency ( $1=$ yes $)$

$0.23 * * * \quad 0.21 * * *$

$0.18 * * *$

Length of stay in community

$0.05 * * * \quad .04 * * \quad 0.02$

\section{Perception of Older Adults about Community}

\section{Characteristic}

Community rating

Influence on community

Interest of local officials

Knowledge of Services

$\begin{array}{ccc}- & -0.01 & -0.01 \\ - & 0.08 * * * & 0.07 * * * \\ - & 0.04 * & 0.02 \\ - & - & 0.04 * * *\end{array}$

(Table 6, continued) 
Table 6 (continued)

Model 1 Model 2 Model 3

Variance Components

Social engagement Intercept

$\begin{array}{lll}0.00 & 0.00 \quad 0.00\end{array}$

Chi-square statistic

$31.94 * * \quad 33.68 * * * \quad 32.62 * * *$

Level-1 residual

0.75

0.74

0.73

Model Fit Statistics

Deviance

Number of parameters

$\Delta$ in deviance

Df

$* p<.05 . * * p<.01 . * * * p<.001$.
$9021.14 \quad 8982.89 \quad 8936.54$

$\begin{array}{lll}13 & 16 & 17\end{array}$

- $\quad 38.25^{* * *} 46.35^{* * *}$

$\begin{array}{lll}- & 3 & 1\end{array}$ 
Table 7

Summary of Multilevel Modeling for Variables Predicting Older Adults Participation in Religious Activities

\begin{tabular}{lccc}
\hline Fixed Effects & Model 1 & Model 2 & Model 3 \\
\hline Intercept & $0.20^{* * *}$ & $0.15^{* * *}$ & $0.13^{* * *}$
\end{tabular}

\section{Demographic Characteristic}

\begin{tabular}{|c|c|c|c|}
\hline Age & $1.10^{*}$ & $1.12 *$ & $1.14^{* *}$ \\
\hline Gender & $1.63 * * *$ & $1.62 * * *$ & $1.57 * * *$ \\
\hline \multicolumn{4}{|l|}{$(1=$ female $)$} \\
\hline Marital status $(1=$ married $)$ & $1.34 * * *$ & $1.36^{* * *}$ & $1.36^{* * *}$ \\
\hline Education & $1.10^{* *}$ & $1.10^{* *}$ & $1.09 * *$ \\
\hline Employment & 0.95 & 0.94 & 0.94 \\
\hline Health & $1.15 * * *$ & $1.15 * * *$ & $1.14 * * *$ \\
\hline Number of living children & $1.13 * * *$ & $1.12 * * *$ & $1.12 * * *$ \\
\hline Income & $0.94 * *$ & $0.94 * *$ & $0.93 * *$ \\
\hline Someone to call in emergency $(1=\mathrm{yes})$ & 1.17 & 1.14 & 1.10 \\
\hline Length of stay in community & $1.17 * * *$ & $1.17 * * *$ & $1.13 * * *$ \\
\hline
\end{tabular}

\section{Perception of Older Adults about Community}

Characteristic

Community rating

$\begin{array}{lll}- & 1.00 & 0.99 \\ - & 1.21 * * * & 1.20 * * * \\ - & 0.98 & 0.95\end{array}$

Knowledge of Services

$\begin{array}{lll}- & - & 1.05 * * *\end{array}$

(Table 7 , continued) 
Table 7 (continued)

Model $1 \quad$ Model $2 \quad$ Model 3

Final Estimation of Variance Components

\begin{tabular}{llll} 
Variance & 0.128 & 0.125 & 0.136 \\
SE & 0.358 & 0.353 & 0.368 \\
P-value & 0.000 & 0.000 & 0.000 \\
& & & \\
\hline$* p<.05 . * * p<.01 . * * * p<.001$. & & &
\end{tabular}


Table 8

Summary of Multilevel Modeling for Variables Predicting Older Adults Participation in Social Activities

\begin{tabular}{lccc}
\hline Fixed Effects & Model 1 & Model 2 & Model 3 \\
\hline Intercept & $0.20 * * *$ & $0.14 * * *$ & $0.11^{* * *}$
\end{tabular}

\section{Demographic Characteristic}

$\begin{array}{llll}\text { Age } & 0.94 & 0.94 & 0.96 \\ \text { Gender } & 1.09 & 1.09 & 1.05 \\ (1=\text { female }) & & & \\ \text { Marital status (1=married) } & 0.89 & 0.90 & 0.90 \\ \text { Education } & 1.30^{* * * *} & 1.31^{* * *} & 1.29 * * * \\ \text { Employment } & 0.95 & 0.95 & 0.95 \\ \text { Health } & 1.22^{* * * *} & 1.20^{* * *} & 1.19 * * * \\ \text { Number of living children } & 1.12^{* * *} & 1.11^{* * *} & 1.11^{* * *} \\ \text { Income } & 1.25^{* * * *} & 1.25^{* * *} & 1.24 * * * \\ \text { Someone to call in emergency }(1=y e s) & 1.44^{* * *} & 1.39^{* * *} & 1.32^{* * *} \\ \text { Length of stay in community } & 1.02 & 1.01 & 0.97\end{array}$

\section{Perception of Older Adults about Community}

Characteristic

Community rating

$\begin{array}{lll}- & 1.01 & 1.00 \\ - & 1.11 * * & 1.10 * \\ - & 1.15 * * * & 1.11 * \\ - & - & 1.07 * * *\end{array}$

Knowledge of Services

(Table 8, continued) 
Table 8 (continued)

Model $1 \quad$ Model $2 \quad$ Model 3

\section{Final Estimation of Variance Components}

\begin{tabular}{lrrr} 
Variance & 0.047 & 0.052 & 0.042 \\
SE & 0.218 & 0.228 & 0.205 \\
P-value & 0.000 & 0.000 & 0.000 \\
& & & \\
\hline$* p<.05 . * * p<.01 . * * * p<.001$. & & &
\end{tabular}


Table 9

Summary of Multilevel Modeling for Variables Predicting Older Adults Participation in Family Activities

\begin{tabular}{l}
\hline Fixed Effects \\
\hline Intercept \\
Demographic Characteristic
\end{tabular}

Age

Gender

$(1=$ female $)$

Marital status ( $1=$ married $)$

Education

Employment

Health

Number of living children

Income

Someone to call in emergency ( $1=$ yes $)$

Length of stay in community
Model 1 Model 2 Model 3

$0.73 \quad 0.54^{*} \quad 0.43^{* *}$

0.91

0.93

$1.37 * * *$

$1.37 * * *$

$1.31 * * *$

$0.80 * \quad 0.80 * \quad 0.81 *$

$1.16^{* * *} \quad 1.17 * * * \quad 1.15^{* *}$

$0.89 * *$

$0.88^{* *} \quad 0.88^{* *}$

$1.23 * * * \quad 1.22 * * * \quad 1.21 * * *$

$1.16^{* * *} \quad 1.16^{* * *} \quad 1.15^{* * *}$

$1.14 * * * \quad 1.14 * * * \quad 1.13 * * *$

$1.88 * * * \quad 1.82 * * * \quad 1.74 * * *$

$\begin{array}{lll}1.01 & 1.00 \quad 0.95\end{array}$

\section{Perception of Older Adults about Community}

\section{Characteristic}

Community rating

$\begin{array}{lll}- & 0.99 & 0.99 \\ - & 1.09 & 1.07 \\ - & 1.13 * & 1.09 \\ - & - & 1.08 * * *\end{array}$

Knowledge of Services

(Table 9, continued) 
Table 9 (continued)

Model $1 \quad$ Model $2 \quad$ Model 3

Final Estimation of Variance Components

\begin{tabular}{llll} 
Variance & 0.039 & 0.038 & 0.024 \\
SE & 0.198 & 0.196 & 0.156 \\
P-value & 0.001 & 0.001 & 0.012 \\
& & & \\
\hline$* p<.05 . * * p<.01 . * * * p<.001$. & & &
\end{tabular}




\section{Appendix C}

\section{Selected Study Variables from CPOA 2002 Questionnaire}

Q. 1 What is (NAME's) age?

(50-120) YEARS

DON'T KNOW .............................................. $\mathrm{d}$

REFUSED …................................................

Q. 2 (Are you/Is [NAME]) male or female?

MALE ........................................................m

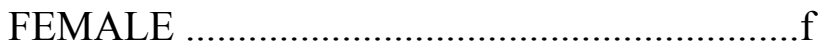

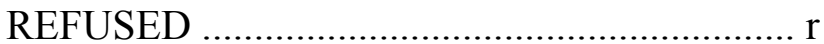

Q. 3 Are you currently married, widowed, divorced, separated, or have you never been married?

MARRIED............................................... 1

WIDOWED …………………………….... 2

DIVORCED ................................................ 3

SEPARATED................................................ 4

NEVER MARRIED............................................ 5

DON'T KNOW .............................................. d

REFUSED ..................................................

Q. 4 What is the highest grade or year of school (you/NAME) completed?

LESS THAN HIGH SCHOOL............................ 1

HIGH SCHOOL/GED...................................... 2

SOME COLLEGE ……....................................... ..

COLLEGE DEGREE (4 YEAR) …......................

ADVANCED DEGREE..................................... 5

DON'T KNOW ............................................. d

REFUSED .................................................. 
Q. 5 (Are you/Is [NAME]) now employed full-time, part-time, or (are you/is [NAME] not employed for pay?

\begin{tabular}{|c|c|}
\hline \\
\hline & \\
\hline NOT EMPLOYED. & \\
\hline RETIRED......... & \\
\hline $\begin{array}{l}\text { RETIRED............ } \\
\text { HOMEMAKER ... }\end{array}$ & \\
\hline DISABLED & \\
\hline ON'T KNOW & \\
\hline EFUSED ....................... & \\
\hline
\end{tabular}

Q.6 In general, would you say (your/NAME's) health is ...

Excellent, ..................................................... 1

Very good, ................................................... 2

Good, ......................................................... 3

Fair, or ....................................................... 4

Poor? ..................................................... 5

DON'T KNOW ...............................................

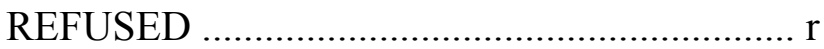

Q. 7 How many living children (do you/does [NAME]) have?

$(0-20)$ NUMBER

DON'T KNOW..................................................

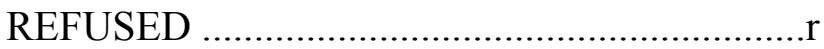

Q. 8 Last year, that is in the year 2001, approximately what was (your/NAME's) and [your spouse's/his/her spouse's) total income before taxes from all sources?

Less than $\$ 10,000, \ldots \ldots \ldots \ldots \ldots \ldots \ldots \ldots \ldots \ldots \ldots \ldots \ldots \ldots \ldots . . .1$

At least $\$ 10,000$ but less than $\$ 20,000, \ldots \ldots \ldots . .2$

At least $\$ 20,000$ but less than $\$ 30,000, \ldots \ldots \ldots \ldots . .3$

At least $\$ 30,000$ but less than $\$ 40,000, \ldots \ldots \ldots \ldots . .4$

At least $\$ 40,000$ but less than $\$ 50,000, \ldots \ldots \ldots \ldots . . .5$

At least $\$ 50,000$ but less than $\$ 75,000, \ldots \ldots \ldots . .6$

At least $\$ 75,000$ but less than $\$ 100,000 \ldots, \ldots \ldots .7$

$\$ 100,000$ or more? .......................................... 8

DON'T KNOW................................................

REFUSED ………….................................... 
Q. 9 Is there someone, other than the police or emergency services, who

(you/NAME) could call on at any hour should some emergency occur?

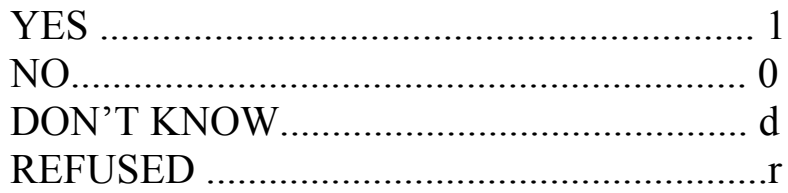

Q. 10 How many years have you lived in (COMMUNITY)?

(0-120) YEARS

ALL THEIR LIFE...................................... a

DOESN'T LIVE IN COUNTY .....................n

DON'T KNOW........................................... d

REFUSED ..................................................r

Q. 11 Overall, how would (you/NAME) rate (COMMUNITY) as a place to live ... .

Excellent, ................................................ 1

Very good, ............................................. 2

Good, ,.......................................................... 3

Fair, or .................................................. 4

Poor?.......................................................

DON'T KNOW ...........................................d

REFUSED ...................................................

Q. 12 How much influence do you think people like yourself can have in making (COMMUNITY) a better place to live? Would you say ...

A lot, ........................................................ 1

Some, ..................................................... 2

Not very much, or .................................. 3

None?....................................................... 4

DON'T KNOW .......................................... d

REFUSED ................................................... 


\section{Q. 13 To what extent do you think that local elected officials, such as officials in} your city or town council or county government, take into account the interests and concerns of older people? Would you say ...

Quite a lot,

Somewhat, . .1

Not very much, or

Not at all? ......................................................

DON'T KNOW ..............................................

REFUSED …........................................ $\mathrm{r}$

\section{Q. 14 I'm going to read a list of various services or facilities for older adults that are} available in some communities. For each one, please tell me if it is available in

(COMMUNITY). $\quad \mathrm{YES}=1 \mathrm{NO}=0$, DON'T KNOW=d REFUSED $=\mathrm{r}$
a. Senior Center
b. Adult day program
c. Special service that helps with chores or around the house, such as light housekeeping
d. Meals-on-wheels, home delivered meals, or other senior lunch programs e. Telephone helpline for information or referrals
e. A special program that provides help with home repairs, like with the roof or windows
f. Visiting nurse such as an $\mathrm{RN}$ who comes to your home
g. Home health aide, personal care attendant, or other assistant who helps with personal needs
h. A special door to door transportation program
i. Nursing home
j. Assisted living facility
k. End of life or hospice care

Q. 15 During the past week, did (you/NAME): $(y e s=1$, no $=0$, don't know $=\mathrm{d}$, refused $=$ r)

a. Go to church, temple, or another place of worship for services or other activities?

b. Go to a movie, play, concert, restaurant, sporting event, club meeting, card game, or other social activity?

c. Get together with family, friends or neighbors in any other setting? 


\section{Reference List}

AARP. (1988). Attitudes of Americans over 45 years of age on volunteerism.

Washington, DC: Hamilton, Frederick \& Schneiders.

Antonucci, T. (1990). Social supports and social relationships. In R. H. Binstock \& L.K. George (Eds.), Handbook of aging and the social sciences (pp. 205-226). San Diego, CA: Academic Press.

Bambrick, P., \& Bonder, B. (2005). Older adults' perceptions of work. Work: A Journal of Prevention, Assessment \& Rehabilitation, 24(1), 77-84.

Barlow, J., \& Hainsworth, J. (2001). Volunteerism among older people with arthritis. Ageing and Society, 21, 203-217.

Beach, S. R., Schulz, R., \& Yee, J. L. (2000). Negative and positive health effects of caring for a disabled spouse: Longitudinal findings from the caregiver health effects study. Psychology \& Aging, 15, 259- 271.

Beaubien, J. M., Hamman, W. R., Holt, R. W., \& Boehm-Davis, D. A. (2001). The application of hierarchical linear modeling (HLM) techniques in commercial aviation research. Proceedings of the $11^{\text {th }}$ Annual Symposium on Aviation Psychology, Columbus, OH: The Ohio State University Press.

Berkman, L. F., Seeman, T. E., \& Albert, M. (1995). High, usual, and impaired functioning in community-dwelling older men and women: Findings from the MacAurthur Foundation Research Network on Successful Aging. Journal of Clinical Epidemiology, 46, 1129-1140.

Black, W., \& Brown, R. (2004, July). Shoring up the infrastructure for long-term care: What do vulnerable older adults know about their options? (Mathematica Policy 
Research Issue Brief No. 1). Retrieved June 21, 2005, from http://www.mathematica-mpr.com/publications/PDFs/shoringup.pdf

Black, B., \& DiNitto, D. (1994). Volunteers who work with survivors of rape and battering: Motivations, acceptance, satisfaction, length of service, and gender differences. Journal of Social Service Research, 20, 73-97.

Bolda, E. J., Lowe, J. I., Maddox, G. L., \& Patnaik, B. S. (2005). Community partnerships for older adults: A case study. Families in Society: The Journal of Contemporary Social Services, 86(3), 411-418.

Brown, R., \& Black, W. (2005). The Community partnerships for older adults (CPOA) program: Survey of Older Adults data documentation [United States]. ICPSR04301-v1. Washington, DC: Mathematica Policy Research, Inc. [producer]. Ann Arbor, MI: Inter-university Consortium for Political and Social Research [distributor], 2005-10-26.

Bryk, A. S., \& Raudenbush, S. W. (1992). Hierarchical linear models: Applications and data analysis methods (1st ed.). Thousand Oaks, CA: Sage.

Bukov, A., Maas, I., \& Lampert, T. (2002). Social participation in very old age: Crosssectional and longitudinal findings from BASE. Journal of Gerontology: Psychological Sciences, 57B(6), P510-P517.

Butler, R. N. (2002). The study of productive aging. Journal of Gerontology: Social Sciences, 57B(6), S323.

Call, K. T., Finch, M. A., Huck, S. M., \& Kane, R. A. (1999). Caregiver burden from a social exchange perspective: Caring for older people after hospital discharge. Journal of Marriage \& the Family, 61(3), 688-699. 
Caro, F. G., \& Bass, S. A. (1995). Dimensions of productive engagement. In S. Bass (Ed.), Older and active (pp. 204-216). New Haven, CT: Yale University Press. Chambre, S. M. (1993). Volunteerism by elders: Past trends and future prospects. The Gerontologist, 33(2), 221-228.

Chen, S.-Y. \& Fu, Y.-C. (2008). Leisure participation and enjoyment among the elderly: Individual characteristics and sociability. Educational Gerontology, 34(10), 871889.

Cheung, F. Y.-L., Tang, C. S.-k., \& Yan, E. C.-W. (2006). Factors influencing intention to continue volunteering: A study of older Chinese in Hong Kong. Journal of Social Service Research, 32(4), 193-209.

Choi, N. G., \& Dinse, S.-L. (1998). Challenges and opportunities of the aging population: Social work education and practice for productive aging. Educational Gerontology, 24(2), 159-173.

Cnaan, R. A., \& Cascio, T. A. (1999). Performance and commitment: Issues in management of volunteers in human service organizations. Journal of Social Service Research, 24(3/4), 1-37.

Conner, K. A., Dorfman, L. T., \& Thompkins, J. B. (1985). Life satisfaction of retired professors: The contribution of work, health, and length of retirement. Educational Gerontology, 11, 337-347.

Connidis, I. A., \& McMullin, J. A. (1992). Getting out of the house: The effect of childlessness on social participation and companionship in later life. Canadian Journal of Aging, 11(4), 370-386. 
Cook, D. J. (2007, June 2). Adults using smart environment technologies. Retrieved February 15, 2008, from www.axistive.com/adults-using-smart-environmenttechnologies.html

Cortina, J. M. (1993). Interaction, nonlinearity, and multicollinearity: Implications for multiple regression. Journal of Management, 19(4), 915-922.

Dunteman, G. H., \& Ho, M. R. (2006). An introduction to generalized linear models. Thousand Oaks, CA: Sage.

Donnenwerth, G. V., \& Foa, U. G. (1974). Effects of resource class on retaliation to injustice in interpersonal exchange. Journal of Personality and Social Psychology, 29, 785-793.

Doty, P., Jackson, M. E., \& Crown, W. (1998). The impact of female caregivers employment status on patterns of formal and informal eldercare. The Gerontologist, 38, 331-341.

Fabrigoule, C., Letenneur, L., \& Dartigues, J. F. (1995). Social and leisure activities and risk of dementia: A prospective longitudinal study. Journal of the American Geriatrics Society, 43, 485-490.

Fischer, L. R., Mueller, D. P., \& Cooper, P. W. (1991). Older volunteers: A discussion of the Minnesota Senior Study. The Gerontologist, 31(2), 183-194.

Fischer, L. R., \& Schaffer, K. B. (1993). Older volunteers: A guide to research and practice. Newbury Park, CA: Sage.

Foa, U. G., \& Foa, E. B. (1974). Societal structures of the mind. Springfield, IL: Thomas. Gallagher, S. K. (1994). Older people giving care: Helping family and community. Westport, CT: Auburn House. 
George, L. K. (1978). The impact of personality and social status factors upon levels of activity and psychological well-being. Journal of Gerontology, 33, 840-847.

Glass, T. A., Mendes de Leon, C. F., \& Marottoli, R. A. (1999). Population based study of social and productive activities as predictors of survival among elderly Americans. BMJ, 319, 478-483.

Harvard School of Public Health/Metlife Foundation. (2004). Reinventing aging: Baby boomers and civic engagement. Boston: Harvard School of Public Health, Center for Health Communication.

Herzog, A. R., \& Morgan, J. S. (1993). Formal volunteer work among older Americans. In S. A. Bass, F. G. Caro, \& Y.-P. Chen. (Eds.), Achieving a productive aging society (pp. 119-142). Westport, CT: Auburn House.

Herzog, A. R., Kahn, R. L., Morgan, J. N., Jackson, J. S., \& Antonucci, T. C. (1989). Age differences in productive activities. Journal of Gerontology: Social Sciences, 44, S129-S138.

Herzog, A. R., Ofstedal, M. B., \& Wheeler, L. M. (2002). Social engagement and its relationship to health. Clinics in Geriatric Medicine, 18, 593-609.

Hill, M. S. (1985). Patterns of time use. In F. T. Juster \& F. P. Stafford (Eds.), Time, goods, and wellbeing. Ann Arbor, MI: University of Michigan.

Hinterlong, J. E. (2006). Race disparities in health among older adults: Examining the role of productive engagement. Health \& Social Work, 31(4), 275-288.

Hinterlong, J. E. (2008). Productive engagement among older Americans: Prevalence, patterns, and implications for public policy. Journal of Aging \& Social Policy, 20 (2), 141-164. 
Hinterlong, J. E., Morrow-Howell, N., \& Rozario, P. A. (2007). Productive engagement and late life physical and mental health: Findings from a nationally representative panel study. Research on Aging, 29, 348-370.

Hinterlong, J., Morrow-Howell, N., \& Sherraden, M. (2001). Productive aging: Principles and perspectives. In N. Morrow-Howell, J. Hinterlong, \& M. Sherraden (Eds.), Productive aging: Concepts and controversies (pp. 4-17). Baltimore: Johns Hopkins University Press.

Hultsch, D. F., Small, B. J., \& Hertzog, C. (1999). Use it or lose it: Engaged lifestyle as a buffer of cognitive decline in aging? Psychology \& Aging, 14, 245-263.

Ingersoll-Dayton, B., Morgan, D., \& Antonucci, T. (1997). The effects of positive and negative social exchanges on aging adults. Journal of Gerontology: Social Sciences, 52B(4), S190-S199.

Johnson, R. W., \& LoSasso, A. T. (2000, February). The trade-off between hours of paid employment and time assistance to elderly parents at midlife. Retrieved March 25, 2008, from www.urbaninstitute.org/uploaded PDF/ elderly-parents.pdf

Kellet, K. (2004). Productive aging: Concepts and challenges. Educational Gerontology, 30(8), 711-712.

Keyes, C. L. M. (2002). The exchange of emotional support with age and its relationship with emotional well-being by age. Journals of Gerontology, 57B(6), P518-P525.

Klumb, P. L. (2004). Benefits from productive and consumptive activities. Social Indicators Research, 67, 107-127. 
Klumb, P. L., \& Baltes, M. M. (1999). Time use of old and very old Berliners: Productive and consumptive activities as functions of resources. Journal of Gerontology: Social Sciences, 54B(5), S271-S278.

Lammers, J. C. (1991). Attitudes, motives, and demographic predictors of volunteer commitment and service duration. Journal of Social Service Research, 14, $125-$ 140.

Lawton, M. P. (1985). Activities and leisure. Annual Review of Gerontology and Geriatrics, 5, 127-164.

Lawton, M. P., Nahemow, L., \& Teaff, J. (1975). Housing characteristics and the wellbeing of elderly tenants in federally assisted housing. Journal of Gerontology, 30, 601-607.

Lemke, S., \& Moos, R. H. (1981). The superpersonal environments of sheltered care settings. Journal of Gerontology, 36, 233-243.

Lemke, S., \& Moos, R. H. (1989). Personal and environmental determinants of activity involvement among elderly residents of congregate facilities. Journal of Gerontology: Social Sciences, 44(4), S139-S148.

Litwin, H. (2000). Activity, social network, and well-being: An empirical examination. Canadian Journal on Aging, 19, 343-362.

Luoh, M. C., \& Herzog, A. R. (1999, November). Mortality and morbidity outcomes of volunteer and paid work in old age. Poster presented at the 52nd Annual Scientific Meeting of the Gerontological Society of America, San Francisco, CA. Marriott Senior Living Services. (1991). Marriott Seniors Volunteerism Study. Washington, DC: U.S. Administration on Aging. 
Martinson, M., \& Minkler, M. (2006). Civic engagement and older adults: A critical perspective. Gerontologist, 46(3), 318-324.

Mathers, C. D., \& Schofield, D. (1998). The health consequences of unemployment: The evidence. Medical Journal of Australia, 168, 178-182.

Maturing of America. (2007). A blueprint for action: Developing a livable community for all ages. Washington, DC: National Association of Area Agencies on Aging, Partners for Livable Communities \& MetLife Foundation.

Mendes de Leon, C. F., Glass, T. A., \& Beckett, L. A. (1999). Social networks and disability transitions across eight intervals of yearly data in the New Haven EPESE. Journal of Gerontology: Social Sciences, 54B(3), S162-S172.

Menec, V. H. (2003). The relation between everyday activities and successful aging: A 6year longitudinal study. Journal of Gerontology: Social Sciences, 58B(2), S74S82.

Menec, V. H., \& Chipperfield, J. G. (1997). The interactive effect of perceived control and functional status on health and mortality among young-old and old-old adults. Journal of Gerontology, 52, 118-126.

Mjelde-Mossey, L. A., \& Chi, I. (2004). Gender differences in expectations predictive of volunteer experience among older Chinese professionals in Hong Kong. Journal of Ethnic \& Cultural Diversity in Social Work, 13(4), 47-64.

Musick, M. A., Herzog, A. R., \& House, J. S. (1999). Volunteering and mortality among older adults: Findings from a national sample. Journal of Gerontology: Social Sciences, 54B(3), S173-S180. 
Newsom, J. T., Nishishiba, M., Morgan, D. L., \& Rook, K. S. (2003). The relative importance of three domains of positive and negative social exchanges: A longitudinal model with comparable measures. Psychology \& Aging, 18(4), 746754.

O'Reilly, P., \& Caro, F. G. (1994). Productive aging: An overview of the literature. Journal of Aging \& Social Policy, 6(3), 39-71.

Ofstedal, M. B., Wheeler, L., \& Herzog, A. R. (2000). The link between activity and mental health in older adults. Poster presented at the 2000 Annual Meeting of the American Psychological Association, Washington, DC.

Omoto, A. M., \& Snyder, M. (1995). Sustained helping without obligating: Motivation, longevity of service, and perceived attitude change among aids volunteers. Journal of Personality and Social Psychology, 68, 671-686.

Pai, M. (2008). Later life social engagement and health. Unpublished doctoral dissertation, Florida State University.

Penner, L. A., \& Finkelstein, M. A. (1998). Dispositional and structural determinants of volunteerism. Journal of Personality and Social Psychology, 74, 525-537.

Peters-Davis, N. D., Burant, C. J., \& Braunschweig, H. M. (2001). Factors associated with volunteer behavior among community dwelling older persons. Activities, Adaptation \& Aging, 26(2), 29-44.

Raudenbush, S. W., Bryk, A. S., \& Congdon, R. T. (2004). HLM 6 [software]. Chicago: Scientific Software International.

Reid, M. G. (1934). Economics of household production. New York: John Wiley and Sons. 
Ross, C. E., \& Mirowsky, J. (1995). Does employment affect health? Journal Health Social Behavior, 36, 230-243.

Rowe, R. L., \& Kahn, R.L. (1998). Successful aging. New York: Pantheon/Random House.

Rozario, P. A., Morrow-Howell, N., \& Hinterlong, J. E. (2004). Role enhancement or role strain: Assessing the impact of multiple productive roles on older caregiver well-being. Research on Aging, 26(4), 413-428.

Schaie, K. W. (1984). Midlife influences upon intellectual functioning in old age. International Journal of Behavioral Development, 7, 463-478.

Schulz, R., \& Beach, S. R. (1999). Caregiving as a risk factor for mortality: The caregiver health effects study. Journal of the American Medical Association, 282, 22152219.

Seongsu, K., \& Feldman, D. C. (2000). Working in retirement: The antecedents of bridge employment and its consequences for quality of life in retirement. Academy of Management Journal, 43(6), 1195-1210.

Sherman, S. R. (1974). Leisure activities in retirement housing. Journal of Gerontology, $29,325-335$.

Smith, J. K. (2003, July 26). There's growing need for older adults to stay in their own surroundings. Retrieved February 15, 2008, from www.globalaging.org/elderrights/us/caregiver.htm

Stathi, A., Fox, K. R., \& McKenna, J. (2002). Physcial activity and dimensions of subjective well-being in older adults. Journal of Aging and Physical Activity, 10, 76-92. 
Stevens-Ratchford, R., \& Cebulak, B. J. (2004). Living well with arthritis: A study of engagement in social occupations and successful aging. Physical and Occupational Therapy in Geriatrics, 22(4), 31-52.

Stevens-Ratchford, R., \& Diaz, T. (2003). Promoting successful aging through occupation. An examination of engagement in life: A look at aging in place, occupation and successful aging. Activities, Adaptation \& Aging, 27(3-4), 19-37.

Szafran, R. F. (2000, September). Age-adjusted labor force participation rates, 19602045. Monthly Labor Review, 125, 25-37.

Taylor, R. J., \& Chatters, L. M. (1991). Nonorganizational religious participation among elderly Black adults. Journal of Gerontology: Social Sciences, 46, S103-S111.

Taylor, R. J., Chatters, L. M., \& Jackson, J. S. (2007a). Religious and spiritual involvement among older African Americans, Caribbean Blacks, and nonHispanic Whites: Findings from the National Survey of American Life. Journal of Gerontology: Social Sciences, 62B(4), S238-S250.

Taylor, R. J., Chatters, L. M., \& Jackson, J. S. (2007b). Religious participation among older Black Caribbeans in the United States. Journal of Gerontology: Social Sciences, 62B (4), S251-S256.

Taylor, R. J., Chatters, L. M., \& Levin, J. S. (1992). Antecedents and dimensions of religious involvement among older Black adults. Journal of Gerontology: Social Series, 47, S269-S278.

Thompson, G. B. (1973). Work versus leisure roles: An investigation of morale among employed and retired men. Journal of Gerontology, 28, 339-344. 
Unger, J. B., Johnson, C. A., \& Marks, G. (1997). Functional decline in the elderly: Evidence for direct and stress-buffering protective effects of social interactions and physical activity. Annals of Behavioral Medicine, 19, 152-160.

U.S. Census Bureau. (2002). American housing survey for the United States: 2001 (Current Housing Reports, Series H150/01). Washington, DC: U.S. Government Printing Office.

Van der Meer, M. (2006). Productivity among older people in the Netherlands:

Variations by gender and the socio-spatial context in 2002-03. Ageing \& Society, 26(6), 901-923.

Wahrendorf, M., Von dem Knesebeck, O., \& Siegrist, J. (2006). Social productivity and well-being of older people: Baseline results from the SHARE Study. European Journal of Ageing, 3(2), 67-73.

West, G. E., Delisle M. A., \& Simard, C. (1996). Leisure activities and service knowledge and use among the rural elderly. Journal of Aging and Health, 8(2), 254-279.

Westendorp, R. G. (2006). What is healthy aging in the 21 st century? American Journal of Clinical Nutrition, 83(2), 404S-409S. 


\section{VITA}

Seema Sehrawat was born in northern IndiaberaZ KCHIgrowing up moved DORYH India because of her father's job in the Indian Air Force. She earned her bachelor's degree in social work from Delhi University, India, her master degree in social work from Tata Institute of Social Sciences, Mumbia, India and her $\mathrm{PhD}$ in social work from University of Missouri. Seema spent her social work career providing services to drug dependents and their families. She was also involved in various social action groups in India, advocating for social justice for the oppressed.

Seema's dissertation research looked at predictors of social engagement among community-dwelling adults. Currently she lives in Columbia, Missouri, and teaches in the School of Social Work at University of Missouri. She is getting ready to move to Chico, California for her new job as an assistant professor at California State University, Chico. 